\title{
VULNERABILIDADE EXTERNA E OS CICLOS ECONÔMICOS NO BRASIL PÓS-PLANO REAL
}

\author{
Gisele Ferreira Tiryaki, Diego Nunes Teixeira e Vinícius Ferreira de \\ Araújo *
}

\begin{abstract}
Resumo
Economias emergentes dependem de um fluxo contínuo de recursos externos e são suscetíveis a ataques especulativos contra sua moeda, em razão de choques externos ou de fundamentos macroeconômicos frágeis. Este artigo tem por objetivo avaliar o impacto da fragilidade externa nos ciclos econômicos do Brasil entre 1996 e 2019. O trabalho utiliza o modelo de fator dinâmico para derivar um indicador de vulnerabilidade externa e o método dos momentos generalizado para analisar a importância da vulnerabilidade externa para as flutuações econômicas. Os resultados mostram que uma crescente vulnerabilidade externa está associada à expansão da atividade econômica no Brasil.
\end{abstract}

Palavras-chave: vulnerabilidade externa, ciclos econômicos, fator dinâmico.

Códigos JEL: E32, F41, C32.

\begin{abstract}
Emerging market economies rely on a steady inflow of external resources and are susceptible to currency speculative attacks due to external shocks or to weak macroeconomic fundamentals. This paper aims at evaluating the impact of external fragility on business cycles in Brazil between 1996 and 2019. A dynamic factor model is used to derive an external vulnerability index, and econometric estimations based on the generalized method of moments are conducted to verify whether external vulnerability is relevant to economic fluctuations. The results indicate that an increased external vulnerability is associated with economic booms in Brazil.
\end{abstract}

Keywords: external vulnerability, business cycles, dynamic factor. JEL codes: E32, F41, C32.

DOI: http://dx.doi.org/10.11606/1980-5330/ea 173917

\footnotetext{
* Departamento de Economia. Universidade Federal da Bahia. E-mail: gtiryaki@ufba.br
} 


\section{Introdução}

A importância dos choques externos para os ciclos econômicos no mercado doméstico tem sido objeto de estudo de uma ampla literatura. Países emergentes, em particular, são mais suscetíveis a interrupções abruptas no fluxo de recursos externos (sudden stops) e a ataques especulativos contra a moeda doméstica, fatores que podem provocar ou agravar um processo recessivo (Ocampo 2011, Frankel \& Saravelos 2012, Reyes-Heroles \& Tenorio 2017, Siklos 2018).

Mudanças nas condições de financiamento no mercado internacional podem levar os investidores a buscar reequilibrar seus portfolios, direcionando recursos para mercados mais robustos e reduzindo a disponibilidade de recursos para países emergentes. De acordo com Kaminsky et al. (2004) e Ocampo (2011), flutuações no fluxo de capitais externos contribuem para ampliar as vulnerabilidades macroeconômicas, particularmente em países de renda mediana. As transações externas têm um forte impacto sobre a economia, via oscilações no comércio de bens e serviços, na disponibilidade de financiamento externo, nos spreads de risco associados às taxas de juros e nas taxas de câmbio.

Tradicionalmente, vincula-se a vulnerabilidade externa de um país ao fraco desempenho da economia doméstica, à fragilidade das instituições de governança e a políticas macroeconômicas equivocadas (Krugman 1999). No entanto, a crescente inserção das economias emergentes no mercado internacional deixou-as expostas a choques externos mesmo quando seus fundamentos macroeconômicos estão robustos (Calvo \& Talvi 2008, Kaltenbrunner \& Painceira 2014).

A integração econômica e financeira entre as economias contribui para que os choques externos, principalmente aqueles que ocorrem em economias desenvolvidas de grande porte, sejam transmitidos para o mercado doméstico (Frankel \& Saravelos 2012, Fernández et al. 2017, Siklos 2018). A transmissão internacional de políticas macroeconômicas se dá especialmente por meio do impacto das variações nas taxas de câmbio, fruto de modificações nas taxas de juros internacionais.

A difusão desses choques pode decorrer da atuação de firmas multinacionais ou via canais financeiros. Cravino \& Levchenko (2016) e Di Giovanni et al. (2018) mostram que subsidiárias de empresas multinacionais reduzem o investimento e emprego de maneira significativa em resposta a crises econômicas nos países de origem de sua empresa controladora, fazendo com que o movimento sincronizado de variáveis agregadas nas duas economias seja mais pronunciado. Já Haas \& Lelyveld (2014) e Demirguc-Kunt et al. (2017) enfatizam os canais financeiros de transmissão: instituições financeiras costumam gerenciar seus riscos de liquidez globalmente, e essa estratégia faz com que a instabilidade no mercado de crédito em economias de grande porte seja transmitida para outros países.

A análise da evolução da economia brasileira mostra que a dinâmica macroeconômica doméstica é influenciada pelo desempenho dos países centrais em virtude de três fatores. Primeiramente, o país comumente precisa absorver recursos externos para financiar seus déficits em transações correntes, causados pelos déficits na balança de serviços e pelas significativas remessas de rendas de investimento direto e de portfólio e do pagamento de juros ao exterior.

Outra razão para a vulnerabilidade da economia brasileira a choques externos é sua pauta de exportações historicamente baseada em commodities. Em 
períodos de grande liquidez internacional, quando se observa o aumento na demanda internacional por bens primários, o volume de exportações do país se eleva e há um expressivo fluxo de recursos financeiros para o Brasil. Já em períodos de recessões financeiras mundiais, a demanda por commodities declina e o país enfrenta um forte fluxo de saída de capitais, que desestabiliza o balanço de pagamentos e a taxa de câmbio.

O terceiro elemento refere-se ao processo de liberalização comercial e financeira experimentado nas últimas décadas por vários países, inclusive pelo Brasil (Van Der Laan et al. 2011). A evidência empírica sugere que a abertura comercial tende a amplificar o impacto de choques nos termos de troca no produto doméstico, enquanto a liberalização financeira reduz marginalmente a volatilidade na produção (Goldfajn \& Minella 2005, Loayza \& Raddatz 2007, Montalbano 2011).

Este trabalho tem por objetivo verificar se a vulnerabilidade externa amplifica os ciclos econômicos no Brasil. Utilizando dados mensais entre $1996 \mathrm{e}$ 2019, derivou-se um indicador de fragilidade externa com base no modelo de fator dinâmico e verificou-se a relação entre vulnerabilidade externa e as flutuações cíclicas da economia por meio do método dos momentos generalizado (GMM). Estabelecer a relação entre vulnerabilidade externa e as flutuações econômicas de curto prazo é um elemento importante para o delineamento e condução das políticas macroeconômicas e para o desenho de regulação macroprudencial. Assim, o presente trabalho busca não somente identificar um indicador de vulnerabilidade externa que possa ser utilizado para a realização de previsões do grau de exposição da economia a choques externos, mas também verificar a relevância dessa vulnerabilidade para o desempenho macroeconômico de curto prazo.

O presente trabalho inova ao utilizar o modelo do fator dinâmico para derivar o indicador de vulnerabilidade externa. Stock \& Watson (2011) mostram que esse modelo permite lidar com uma dificuldade relevante em macroeconomia, que é a existência de uma grande quantidade de variáveis com limitada disponibilidade de observações temporais. Assim, o modelo de fator dinâmico é utilizado no presente trabalho para identificar o fator latente que explica uma parte significativa da variância conjunta de séries temporais relacionadas ao desempenho externo da economia. Além de preservar a informação presente em um conjunto amplo de variáveis e, ao mesmo tempo, ampliar o número de graus de liberdade, Stock \& Watson (2011) também apontam outras vantagens de se derivar fatores latentes, tais como: (i) utilizá-los para construir previsões eficientes de variáveis individuais; (ii) empregá-los como variáveis instrumentais; e (iii) utilizá-los na estimação de vetores autorregressivos do tipo FAVAR (factor-augmented VAR) e de modelos dinâmicos estocásticos de equilíbrio geral (DSGE).

A literatura que se dedica à construção de um indicador de vulnerabilidade externa para o Brasil restringe-se a adotar um arcabouço teórico em particular e não analisa formalmente as características e relações entre as séries temporais (De Paula \& Alves JR 2000, Sarto \& Almeida 2015). O modelo do fator dinâmico adotado aqui permite levar em consideração a não estacionariedade das séries temporais utilizadas, o que não é avaliado pelos referidos autores. Ademais, esses autores não conduzem uma análise econométrica formal da relação entre choques na vulnerabilidade externa e os ciclos econômicos.

A estratégia adotada neste trabalho é semelhante àquela utilizada por Teixeira et al. (2020) e Moura et al. (2020) para mensurar a fragilidade finan- 
ceira e do setor público no Brasil, respectivamente. No entanto, os referidos autores fazem uso de vetores autorregressivos (VAR) para analisar a relação entre fragilidade e ciclos econômicos, enquanto o presente trabalho verifica a importância da fragilidade externa para a volatilidade dos ciclos econômicos por meio do GMM. Os modelos VAR estimados por Teixeira et al. (2020) e Moura et al. (2020) não buscam estabelecer uma relação de causalidade entre o indicador de fragilidade e a estabilidade macroeconômica. O uso do GMM lastreia-se em uma estratégia de identificação definida a partir de modelos teóricos sobre ciclos de negócios, em particular daqueles de tradição novokeynesiana (Hansen \& Singleton 1982, Gali \& Gertler 1999). Nesse trabalho, o objetivo é estimar uma equação de Euler para a produção que incorpore persistência, gastos do governo, fricções financeiras e, em particular, vulnerabilidade externa, aspectos apontados pela literatura como relevantes para a estabilidade macroeconômica.

Os resultados da análise empírica indicaram que a vulnerabilidade externa contribui para as expansões na atividade econômica no Brasil. Esse resultado alinha-se à literatura que argumenta que a vulnerabilidade externa constitui um elemento que, ao mesmo tempo em que favorece a expansão na produção e no emprego, deixa a economia suscetível a choques externos. Gourinchas \& Obstfeld (2012) e Shin (2016) mostram que a apreciação cambial e a elevação do endividamento externo são comumente observadas durante as expansões, mas também são preditores de crises financeiras. As estimações também revelaram resultados condizentes com a literatura: reduções na taxa de juros levam à expansão na atividade econômica, enquanto preços de ativos e o resíduo de Solow se elevam durante expansões.

Além desta introdução, o trabalho possui outras cinco seções. A segunda seção apresenta uma breve revisão da literatura sobre os canais de transmissão dos choques externos para a economia doméstica e discute os trabalhos que analisaram a vulnerabilidade externa da economia brasileira. A terceira seção é dedicada ao detalhamento da estratégia de identificação da análise empírica, enquanto a quarta seção apresenta a metodologia econométrica e a descrição das variáveis. Na quinta seção, os resultados da análise empírica são analisados, enquanto a última seção dedica-se às considerações finais.

\section{Vulnerabilidade Externa e os Ciclos Econômicos}

A integração econômica entre os países promove a eficiência econômica e permite a diversificação de riscos, mas deixa as economias vulneráveis a choques externos. Distúrbios no fluxo de capitais no mercado internacional, dificuldades no acesso ao crédito externo, variações nas taxas de juros e flutuações significativas nos preços de commodities podem gerar processos recessivos ou amplificar flutuações econômicas causadas por desequilíbrios no mercado doméstico. Para Calvo \& Talvi (2008) e Kaltenbrunner \& Painceira (2014), a crescente inserção de países emergentes no mercado global tem deixado a economia doméstica exposta a choques externos, até mesmo quando seus fundamentos macroeconômicos estão robustos.

Ocampo (2011) denomina o regime macroeconômico em que as flutuações de curto prazo são essencialmente influenciadas por choques externos de regime de dominância do balanço de pagamentos. Esse seria o perfil macroeconômico de economias emergentes. De acordo com o autor, choques nos ter- 
mos de troca têm um papel importante para explicar as flutuações econômicas, mas fricções no mercado de financiamento externo são ainda mais relevantes em países caracterizados pela dominância do balanço de pagamentos.

É possível identificar pelo menos três canais de transmissão de choques externos para a economia doméstica: o canal do comércio, o canal financeiro e o canal da incerteza (Rohn et al. 2015). O canal do comércio refere-se aos impactos gerados por contrações na demanda externa por bens e serviços ou choques negativos de oferta. O desaquecimento na demanda reduz preços e volume de exportações, enquanto choques negativos de oferta aumentam o preço de produtos importados, reduzindo as margens de lucros das firmas dependentes de importações e elevando os gastos das famílias.

Países com uma pauta de exportações e importações mais diversificada estão menos expostos a choques oriundos de parceiros comerciais ou flutuações de preços de produtos específicos. No entanto, economias emergentes dependem frequentemente da exportação ou importação de commodities, cujos preços tendem a ser mais voláteis do que os preços de manufaturas.

Loayza \& Raddatz (2007) e Montalbano (2011) afirmam que a abertura comercial amplifica os choques nos termos de troca internacionais e contribui para que crises cambiais se proliferem em um contexto regional. Os países costumam comercializar com seus vizinhos e, se um parceiro comercial experimenta uma forte desvalorização cambial, a economia doméstica perde competitividade. Nesse contexto, a probabilidade de ataques especulativos ou de uma desvalorização intencional se eleva (Glick \& Rose 1999, Easterly \& Kraay 2000).

O segundo canal de transmissão de choques externos é o canal financeiro, que é relacionado ao fluxo de ativos e passivos no mercado internacional. Rohn et al. (2015) salientam que é importante analisar o canal financeiro considerando separadamente os fatores associados ao sistema bancário dos fatores não bancários.

A vulnerabilidade externa do sistema bancário pode resultar da exposição em termos de ativos ou de passivos dos bancos (Ahrend \& Goujard 2014, Haas \& Lelyveld 2014, Demirguc-Kunt et al. 2017). Quando o sistema bancário doméstico incorre em perdas com ativos adquiridos no exterior, é provável que haja uma redução na concessão de crédito no mercado doméstico, desaquecendo a atividade econômica. A exposição em termos de passivos, por sua vez, decorre da dependência significativa do endividamento externo, comprometendo a disponibilidade de recursos para a concessão de crédito no mercado doméstico em períodos de menor liquidez no mercado internacional.

Fatores não bancários que podem levar à vulnerabilidade externa referemse às transações com ações e títulos realizadas no mercado de capitais. Uma deflação de preços de ativos no mercado externo reduz a riqueza financeira das famílias e limita o acesso de recursos via emissão de ações ou títulos por parte das firmas, podendo desaquecer a demanda doméstica. Além disso, um declínio na riqueza financeira de investidores externos pode causar a saída de capitais do país, à medida que esses investidores reequilibram seus portfólios.

Ocampo (2011) afirma que o canal financeiro de transmissão de choques externos se dá particularmente via flutuações na disponibilidade de crédito para o setor privado, afetando o investimento das firmas. Os riscos são mais significativos para países em desenvolvimento, em razão da predominância do endividamento externo de curto prazo e do descasamento cambial entre as 
receitas das firmas, denominadas em moeda doméstica, e as despesas financeiras, denominadas em moeda estrangeira ${ }^{1}$.

O terceiro canal de transmissão de choques externos é o canal da incerteza. Rohn et al. (2015) afirmam que a instabilidade no mercado externo pode levar as famílias a restringirem o consumo. As firmas, por sua vez, tendem a reduzir o investimento quando há expectativa de declínio na demanda externa pelos seus produtos. Adicionalmente, um aumento na incerteza pressiona os custos com empréstimos externos, ao elevar o prêmio de risco das taxas de juros. Bonciani \& Ricci (2020) utilizam um modelo de fatores para derivar um indicador de risco financeiro global e incerteza, e mostram que elevações nesse indicador operam como um choque negativo de demanda, reduzindo a produção, desestimulando o comércio e elevando o desemprego.

A instabilidade financeira em um país pode fazer com que investidores externos reavaliem suas expectativas quanto ao desempenho de países vizinhos com o mesmo perfil de risco. Mudanças abruptas na confiança dos investidores podem levá-los a superestimar a interdependência entre países, gerando uma reversão no fluxo de capitais e provocando uma desvalorização cambial.

Frankel \& Saravelos (2012) mostram que desequilíbrios persistentes nas taxas de câmbio antecedem crises financeiras, particularmente em países em desenvolvimento. Já Siklos (2018) afirma que as taxas de câmbio se distanciam com frequência de sua tendência de longo prazo e essas flutuações impactam negativamente nos setores real e financeiro de uma economia. A volatilidade na taxa de câmbio afeta negativamente o comércio internacional ao elevar a incerteza e os custos de ajustamento de exportadores avessos ao risco, afetando a estrutura da produção, do investimento e das políticas governamentais (Oreiro et al. 2014, Moslares \& Ekanayake 2018).

\subsection{Vulnerabilidade Externa e Estabilidade Macroeconômica no Brasil}

A vulnerabilidade externa do Brasil declinou sensivelmente a partir da adoção do regime de metas de inflação com câmbio flutuante. Políticas macroeconômicas gerenciadas de maneira apropriada e uma melhoria na qualidade da inserção externa vêm promovendo uma maior resiliência do país a crises financeiras e cambiais (Sarto \& Almeida 2015, Ribeiro 2016). Não obstante, economias emergentes estão sujeitas a flutuações no fluxo de capitais de investidores externos. Correa et al. (2012) e Kaltenbrunner \& Painceira (2014) acreditam que o Brasil ainda apresenta uma vulnerabilidade estrutural que se reflete (i) em déficits persistentes no saldo de transações correntes; (ii) na composição do endividamento externo, com um perfil predominante de operações de curto prazo; e (iii) na elevada volatilidade cambial e de taxas de juros.

A literatura que busca estabelecer a importância da vulnerabilidade externa para o desempenho da economia brasileira tem utilizado estratégias empíricas distintas da empregada no presente trabalho. É comum o uso de modelos VAR com a seleção de um número restrito de variáveis para mensurar a vulnerabilidade externa. Utilizar um conjunto menor de variáveis limita o conteúdo informacional que pode ser agregado à análise. A estratégia do presente trabalho de utilizar o modelo do fator dinâmico permite incorporar um

\footnotetext{
${ }^{1}$ Ocampo (2011) salienta que a acumulação de reservas externas e o desenvolvimento do mercado de doméstico de títulos têm o potencial de reduzir a vulnerabilidade externa de economias emergentes. Em especial, deixam os governos desses países menos dependentes de financiamento externo.
} 
conjunto significativo de variáveis, derivando o fator latente que determina o movimento sincronizado dessas variáveis e preservando graus de liberdade.

Goldfajn \& Minella (2005), por exemplo, avaliam a relação entre fluxos de capitais e desempenho macroeconômico, demonstrando que a liberalização financeira e a adoção do câmbio flutuante reduziram a vulnerabilidade externa da economia brasileira no período pós-Plano Real. Esses autores incorporam apenas cinco variáveis associadas às contas externas na estimativa do modelo VAR: transações correntes, fluxo de capitais privados, termos de troca, taxa real de câmbio e spread de juros de títulos soberanos de dívida. De Paula et al. (2012), por sua vez, utilizam índices de liberalização financeira de jure e de facto para mostrar que a liberalização da conta capital e a integração financeira não afetaram estabilidade macroeconômica no Brasil ${ }^{2}$. Já Correa et al. (2012) utilizam modelos GARCH para estimar a volatilidade dos principais componentes da conta financeira do balanço de pagamentos do Brasil e outros países emergentes, e mostram que países que são dependentes de fluxos financeiros de curto prazo estão mais expostos a choques externos.

Já os trabalhos que se dedicaram a derivar um indicador de fragilidade externa não empregaram o modelo do fator dinâmico e, em sua vasta maioria, não estimaram modelos econométricos para analisar a relação entre vulnerabilidade externa e o desempenho econômico de curto prazo. O objetivo desses trabalhos foi analisar a evolução histórica do índice em uma perspectiva meramente descritiva. De Paula \& Alves JR (2000), Sarto \& Almeida (2015) e Salles et al. (2018), por exemplo, utilizam dados do balanço de pagamentos para calcular um índice de fragilidade financeira externa para o Brasil, definido pela razão entre os passivos externos atuais e potenciais do país e sua capacidade de pagamento. Os autores utilizam a taxonomia definida por Minsky (1986) para classificar o grau de fragilidade ao longo do período de análise. Já Barros (2008) segue estratégia semelhante para derivar o indicador de fragilidade externa, mas utiliza esse indicador para estimar um modelo VAR e investigar o impacto da fragilidade externa na taxa de juros doméstica e no desempenho econômico brasileiro entre 1994 a 2006.

Nenhum desses trabalhos que estimaram indicadores de fragilidade externa contempla todas as dimensões de vulnerabilidade externa consideradas pelo presente trabalho. A tentativa de analisar um amplo conjunto de indicadores de vulnerabilidade externa foi feita por Ribeiro (2016), que utilizou variáveis identificadas na literatura para avaliar a exposição de um país a choques externos. Não obstante, esse autor restringiu-se à uma análise descritiva dos dados, não tendo o propósito de derivar um índice de vulnerabilidade ou avaliar seu impacto sobre o desempenho macroeconômico de curto prazo com o uso de modelos econométricos.

\section{Estratégia de Identificação}

A teoria dos ciclos reais de negócios (RBC) constituiu um marco na análise dos ciclos econômicos. Construídos com base em pressupostos Walrasianos de concorrência perfeita e de ausência de externalidades, de assimetria de informação ou de outras imperfeições de mercado, as flutuações econômicas

\footnotetext{
${ }^{2} \mathrm{O}$ índice de jure é uma variável dummy construída utilizando informações sobre mudanças na legislação referentes ao controle de capitais, enquanto o índice de facto é o somatório dos ativos e passivos financeiros em relação ao PIB.
} 
de curto prazo nesses modelos decorriam de choques reais, que desviavam temporariamente as variáveis endógenas - produção, consumo e emprego de sua trajetória de equilíbrio de longo prazo.

Nos primeiros modelos RBC, os ciclos econômicos eram determinados pela dinâmica das variáveis de estado: tecnologia e estoque de capital (Kydland \& Prescott 1982, Long \& Plosser 1983) ${ }^{3}$. Posteriormente, na tentativa de alinhar as simulações com a evidência empírica, os modelos passaram a incluir gastos do governo como uma variável de estado adicional (Christiano \& Eichenbaum 1992). Outras extensões ao modelo básico contemplaram a introdução da moeda e transações externas.

Os modelos RBC para economias abertas pressupunham mobilidade perfeita de capital, o que implicava em uma taxa de juros doméstica igual à taxa internacional (Mendoza 1991, 1995, Correia et al. 1995). A taxa de juros internacional, por sua vez, era definida em termos de preços de ativos comercializados no mercado externo, e assumia-se que esses preços seguiam um processo autorregressivo de primeira ordem. Logo, nesses modelos, as flutuações na vulnerabilidade externa seriam fruto de choques aleatórios na produtividade, nos gastos do governo ou nos termos de troca.

A estratégia empírica do presente trabalho lastreia-se nos modelos DSGE, dada a importância de se incorporar elementos não Walrasianos à análise dos ciclos econômicos (Christiano et al. 2005, Smets \& Wouters 2007). O comportamento cíclico da produção nos modelos DSGE é representado por uma curva IS log-linearizada em torno do estado estacionário. Esta seção tem por objetivo delinear os elementos que compõem a curva IS em um modelo de uma economia aberta de pequeno porte, sujeita à existência de custos de ajustamento do estoque de capital, hábitos de consumo, regras fiscais, concorrência imperfeita, assimetria de informação e rigidez de preços ${ }^{4}$.

O modelo canônico novo-keynesiano é lastreado em três equações básicas, derivadas a partir de escolhas ótimas das famílias, firmas e do banco central, em um contexto de rigidez nominal de preços (Clarida et al. 1999):

$$
\begin{gathered}
y_{t}=E_{t} y_{t+1}-\frac{1}{\theta}\left(r_{t}-E_{t} \pi_{t+1}\right)+u_{t}^{I S} \\
\pi_{t}=\beta E_{t} \pi_{t+1}+\kappa y_{t}+u_{t}^{\pi} \\
r_{t}=\phi_{\pi} E_{t} \pi_{t+1}+\phi_{y} E_{t} y_{t+1}+u_{t}^{M P}
\end{gathered}
$$

em que $E_{t}$ indica o valor esperado de uma variável no período t; $y_{t}=\ln Y_{t}, Y_{t}$ é a produção; $r_{t}$ é a taxa nominal de juros; $p_{t}=\ln P_{t}, P_{t}$ representa o nível geral de preços; e a taxa de inflação é dada por $\pi_{t}=p_{t}-p_{t-1}$. Ademais, $\mathrm{o}$

\footnotetext{
${ }^{3}$ Assumindo-se uma função de produção do tipo Cobb-Douglas aumentativa em trabalho, $Y_{t}=K_{t}^{\alpha}\left(A_{t} L_{t}\right)^{1-\alpha}$, com $0<\alpha<1$, os choques de produtividade, $\widetilde{a}_{t}$, são definidos como desvios de $\ln t$ de sua tendência de longo prazo. $\widetilde{a}_{t}$ é conhecido na literatura como resíduo de Solow.

${ }^{4} \mathrm{O}$ objetivo nesta seção é apresentar as conclusões centrais que servem de base para o modelo empírico a ser testado. A apresentação formal completa dos modelos é encontrada nos trabalhos referenciados.
} 
parâmetro $\theta$ representa o coeficiente de aversão absoluta ao risco dos consumidores $(\theta>0)^{5}$, $\beta$ é a taxa de desconto $(0<\beta<1)$ e $\kappa$ é função de parâmetros do modelo, sendo inversamente relacionado com o grau de rigidez real $(\kappa>0)^{6}$. Os parâmetros $\phi_{\pi}$ e $\phi_{y}$ refletem a importância da estabilidade da inflação e da produção na determinação da taxa de juros pelo banco central $\left(\phi_{\pi}>0 ; \phi_{y} \geq 0\right)$.

A equação (1) representa a curva IS obtida a partir da escolha intertemporal ótima de consumo (equação de Euler). A equação (2) é uma curva de Phillips com expectativas forward-looking, derivada da agregação das escolhas das firmas do nível ótimo de preços $\left(P_{t}\right)$, assumindo que as firmas operam em mercados com concorrência monopolística e enfrentam barreiras para ajustarem seus preços ${ }^{7}$. Já a equação (3) ilustra uma regra de política monetária. Os choques $u_{t}^{I S}, u_{t}^{\pi}$ e $u_{t}^{M P}$ são determinados independentemente, e seguem processos autorregressivos de primeira ordem.

O comportamento cíclico da produção é definido por meio da curva IS loglinearizada em torno do estado estacionário:

$$
\tilde{y}_{t}=E_{t} \tilde{y}_{t+1}-\frac{1}{\theta}\left(\tilde{r}_{t}-E_{t} \tilde{\pi}_{t+1}\right)+u_{t}^{I S}
$$

em que, para uma determinada variável $X_{t}, \widetilde{x}_{t}$ representa os desvios do log natural de $X_{t}$ em torno do seu estado estacionário. Ou seja, $\widetilde{x}_{t}=\ln X_{t}-\ln \bar{X}_{t}$ e $\bar{X}_{t}$ é o valor de $X_{t}$ no estado estacionário. Nessa versão básica do modelo canônico novo-keynesiano, os choques de vulnerabilidade externa, assim como os choques de política fiscal, seriam considerados exógenos e estariam incorporados em $u_{t}^{I S}$. Já os choques de produtividade seriam representados por $u_{t}^{\pi}$, enquanto $u_{t}^{M P}$ representaria as intervenções discricionárias de política monetária.

De acordo com Dennis (2009), a principal dificuldade do modelo canônico é a ausência de um mecanismo que gere persistência, pois os choques exógenos se dissipam rapidamente nas simulações realizadas com o modelo básico, enquanto os dados reais apresentam alto grau de persistência ${ }^{8}$. Para garantir a presença de persistência, o presente trabalho pressupõe a existência de hábitos de consumo e rigidez nominal.

A presença de hábitos de consumo modifica a estrutura original da equação de Euler (Christiano et al. 2005, Ravn et al. 2006, Ascari et al. 2019). Assumir a existência de hábitos de consumo implica na complementaridade do consumo em unidades temporais sucessivas. Ou seja, escolhas passadas de consumo afetam as preferências correntes, fazendo com que mudanças drásticas de consumo sejam custosas. Como em Fuhrer \& Rudebusch (2004), uma equação de Euler com hábitos de consumo poderia ser ilustrada por:

\footnotetext{
${ }^{5}$ Utiliza-se usualmente uma função utilidade do consumidor com grau de aversão relativa ao risco constante.

${ }^{6}$ No modelo canônico, o indicador de rigidez real $(\varphi)$ é igual à elasticidade do salário real em resposta a variações na produção. Quanto maior for essa elasticidade, $\varphi$, menor a rigidez real. $\mathrm{O}$ parâmetro $\kappa$ é definido por: $\kappa \equiv \frac{v[1-(1-v) \beta] \varphi}{1-v}$, em que $v$ é a fração das firmas cujos preços são modificados em $t$ e $(1-v)$ é a fração das firmas com preços rígidos.

${ }^{7}$ Como as firmas não podem ajustar seus preços com frequência, o preço ótimo incorpora a trajetória futura esperada para o nível geral de preços.

${ }^{8} \mathrm{Na}$ ausência de dinâmica endógena, a persistência presente nos dados de produção e inflação só pode ser replicada no modelo canônico com a introdução de choques serialmente correlacionados.
} 


$$
c_{t}=E_{t} c_{t+1}-\frac{1}{\theta}\left(\tilde{r}_{t}-E_{t} \tilde{\pi}_{t+1}\right)+\sum_{i=1}^{I} \tau_{i} c_{t-i}+u_{t}
$$

em que $c_{t}=\ln C_{t}, C_{t}$ é o consumo no período t; e os parâmetros $\tau_{i}$ capturam o grau de persistência. Ascari et al. (2019) apontam que a equação (5) pode ser similarmente definida em termos de $y_{t}$.

Persistência também pode ser obtida quando a curva de Phillips internaliza rigidez de preços. Christiano et al. (2005), por exemplo, pressupõem que as firmas não utilizam continuamente toda a informação disponível. Assumese que, em cada período, uma fração das firmas mantêm seus preços rígidos, gerando um componente inercial, enquanto a fração restante das firmas atualiza seus preços com base nas expectativas para a inflação no futuro. Assim, os autores definem a curva de Phillips Novo-Keynesiana com indexação, modificando a equação (2) para:

$$
\pi_{t}=\gamma \pi_{t-1}+(1-\gamma) E_{t} \pi_{t+1}+\kappa y_{t}+u_{t}^{\pi}
$$

A introdução de regras fiscais, por sua vez, permite explicitar o financiamento do endividamento público, a existência de impostos que distorcem incentivos e movimentos endógenos nos gastos de consumo do governo (Leeper et al. 2010, Uhlig 2010, Fève et al. 2013). O desempenho das contas públicas é fundamental para a estabilidade macroeconômica e, por isso, precisa ser internalizado em modelos teóricos e contabilizado nas estimativas empíricas. As regras fiscais são normalmente representadas por um componente autorregressivo que captura persistência, um componente que reflete a motivação de se estabilizar o endividamento público, uma resposta contemporânea ao nível de produção para ilustrar o mecanismo de estabilização automática, e um termo representando intervenções discricionárias de política fiscal.

Assim como Fève et al. (2013), assume-se que os gastos com consumo pelo governo fazem parte da função de utilidade esperada dos agentes econômicos e são inteiramente financiados com impostos do tipo lump-sum:

$$
G_{t}=\bar{g} G_{t-1}^{\tau_{G}}\left(\frac{Y_{t}}{Y_{t-1}}\right)^{-\kappa_{G}} e^{u_{t}^{G}}
$$

em que $\bar{g}$ é um fator de escala para o nível de gastos no pleno emprego; $\tau_{G}$ captura o grau de persistência nos gastos; $\kappa_{G}$ representa a resposta dos gastos ao crescimento na produção (grau com que os gastos são contracíclicos), $\kappa_{G} \geq$ 0 ; e $u_{t}^{G}$ representa as intervenções discricionárias, que seguem um processo autorregressivo de primeira ordem. Log-linearizando a equação (7) é possível obter a expressão para os desvios do logaritmo natural dos gastos do consumo do governo em relação ao pleno emprego:

$$
\tilde{g}_{t}=\tau_{G} \tilde{g}_{t-1}-\kappa_{G}\left(\tilde{y}_{t}-\tilde{y}_{t-1}\right)+u_{t}^{G}
$$

Em relação às imperfeições no mercado de crédito, vários trabalhos salientam a importância da assimetria de informação entre empreendedores e intermediários financeiros como fonte de amplificação de choques que atingem a 
atividade econômica (Bernanke et al. 1998, Gilchrist et al. 2009). A análise é centrada na importância da posição financeira dos empreendedores e dos custos de verificação incorridos por intermediários financeiros para acessar a robustez dos empreendimentos. Restrições na disponibilidade de recursos para adquirir capital pelos empreendedores e o risco de seus empreendimentos afetam sua habilidade de contratar financiamentos e a taxa de juros nos empréstimos.

No modelo padrão com imperfeições de crédito, as famílias poupam e disponibilizam seus recursos para os empreendedores, com o comportamento das instituições financeiras não sendo explicitamente definido (Bernanke et al. 1998). Na ausência de friç̧ões financeiras, o retorno do capital é igual à taxa de juros livre de risco, definida por $r_{t}$. Com fricções financeiras, o estoque de capital dependerá do patrimônio líquido dos empreendedores $\left(N_{t}\right)$ e de empréstimos financiados com os recursos de poupança das famílias $\left(B_{t}\right)$. Definindo o preço do capital como $Q_{t}$, tem-se:

$$
B_{t}=Q_{t} K_{t+1}-N_{t}
$$

Logo, a alavancagem do empreendedor pode ser definida por $\frac{Q_{t} K_{t+1}}{N_{t}}=1+$ $\frac{b Y_{t}}{N_{t}}$, onde b é a fração da renda das famílias que é poupada.

$\mathrm{O}$ volume ótimo de investimento requer que a diferença entre o retorno esperado no capital $\left(E_{t} R_{t+1}^{k}\right)$ e a taxa de juros livre de risco $\left(R_{t}\right)$ seja igual ao prêmio cobrado com financiamento utilizando recursos externos à firma. $\mathrm{O}$ prêmio, por sua vez, é função da alavancagem da firma, $s(\cdot)$. Logo,

$$
\frac{E_{t} R_{t+1}^{k}}{R_{t}}=s\left(\frac{Q_{t} K_{t+1}}{N_{t}}\right)
$$

em que $s(\cdot)>1$ e $s \prime(\cdot)>0$. Ou seja, quando o volume de investimento se eleva em relação ao patrimônio líquido, o prêmio com o uso de recursos externos cresce.

De acordo com Bernanke et al. (1998), a equação (10) é uma forma equivalente de representar a aquisição ótima de bens de capital, que pode definida por:

$$
Q_{t} K_{t+1}=\psi\left(s_{t}\right) N_{t}
$$

onde $\psi(1)=1$ e $\psi^{\prime}(s)>0$. A equação $(11)$ mostra que, à medida que o retorno esperado no capital cresce em relação à taxa livre de risco, a probabilidade de default declina, permitindo que o empreendedor contrate um volume maior de empréstimos e adquira mais capital.

O patrimônio líquido, por sua vez, é uma variável de estado do modelo, definido como o retorno esperado do empreendedor, líquido do empréstimo pago (Bernanke et al. 1998):

$$
\begin{aligned}
N_{t}= & (1-\lambda) R_{t}^{k} Q_{t-1} K_{t} \\
- & (1-\lambda)\left[R_{t-1}\left(Q_{t-1} K_{t}-N_{t-1}\right)\right. \\
+ & \left.\mu G\left(\bar{\omega}_{t}\right) R_{t}^{k} Q_{t-1} K_{t}\right]+\lambda W^{e}
\end{aligned}
$$


em que $\lambda$ é a taxa de mortalidade dos empreendedores; $\omega_{t}$ são choques idiossincráticos, que afetam o retorno do empreendimento; e $W^{e}$ são transferências para novas startups. O termo $R_{t}^{k} Q_{t-1} K_{t}$ representa o retorno em caso de sucesso. Já o termo entre colchetes representa o pagamento do empréstimo alavancado em $t-1, R_{t-1}\left(Q_{t-1} K_{t}-N_{t-1}\right)$, mais os custos esperados de monitoramento em caso de default, $\mu G\left(\bar{\omega}_{t}\right) R_{t}^{k} Q_{t-1} K_{t}$. Esses custos de auditoria representam uma fração $\mu$ do retorno esperado, enquanto $\bar{\omega}_{t}$ é o valor mínimo do choque idiossincrático que garante o pagamento do empréstimo ${ }^{9}$.

Na presença de custos de ajustamento associados aos investimentos, a loglinearização de $Q_{t}, K_{t}, s_{t}$ e $N_{t}$ em torno do estado estacionário implica que:

$$
\begin{gathered}
\tilde{i}_{t}-\tilde{k}_{t}=\varphi \tilde{q}_{t} \\
\tilde{k}_{t}=\Upsilon \tilde{s}_{t-1}+\tilde{n}_{t-1}-\tilde{q}_{t-1}+\varepsilon_{t}^{C} \\
\tilde{n}_{t}=\frac{\lambda \bar{R} \bar{K}}{\bar{N}}\left(\tilde{r}_{t-1}^{k}-\tilde{r}_{t-1}\right)+\tilde{r}_{t-1}+\tilde{n}_{t-1}+\varepsilon_{t}^{V A}
\end{gathered}
$$

A equação (13) é derivada a partir da escolha do nível ótimo de investimento por parte dos empreendedores, assumindo-se que o $\mathrm{Q}$ de Tobin é função crescente da taxa de investimento ${ }^{10}$. A equação (14) é derivada a partir da equação (11), com $\Upsilon$ indicando como desvios no prêmio de risco em relação ao estado estacionário afetam o estoque de capital, e o termo de erro $\varepsilon_{t}^{C}$ capturando distúrbios exógenos na intermediação de crédito. Já a equação (15) é derivada a partir da equação (12), com $\bar{R}, \bar{K}$ e $\bar{N}$ representando os valores das variáveis no estado estacionário e $\varepsilon_{t}^{V A}$ representando choques exógenos nos valores dos ativos utilizados como colateral (Bernanke et al. 1998). Por fim, assume-se que $\varepsilon_{t}^{C}$ e $\varepsilon_{t}^{V A}$ seguem processos autorregressivos de primeira ordem.

Utilizando as equações (14) e (15), obtém-se os desvios do investimento em relação ao estado estacionário por:

$$
\tilde{i}_{t}=\Upsilon \tilde{s}_{t-1}+\tilde{n}_{t-1}-\tilde{q}_{t-1}+\varphi \tilde{q}_{t}+\varepsilon_{t}^{C}
$$

em que $\widetilde{n}_{t-1}$ é definido pela equação (15).

O elemento final a ser incorporado à análise e que é de interesse particular para este trabalho relaciona-se às transações de uma economia com o mercado internacional. Trabalhos que envolvem economia aberta de pequeno porte assumem que as famílias consomem bens produzidos no mercado doméstico e externo e, possuem uma restrição orçamentária que inclui a aquisição de títulos no mercado doméstico e internacional como forma de poupança (Gali

\footnotetext{
${ }^{9}$ Define-se $G\left(\bar{\omega}_{t}\right) \equiv \int_{0}^{\bar{\omega}_{t}} \omega_{t} F\left(\omega_{t}\right) d \omega_{t}$, em que $F(\omega)$ representa a função de distribuição de probabilidade de $\omega_{t}$.

${ }^{10} \mathrm{~A}$ equação (13) incorpora custos de ajustamento do capital à análise, e é obtida a partir da condição de primeira ordem $Q_{t}=1 / c(\cdot)$, em que $I_{t}$ é o investimento e $c\left(\frac{I_{t}}{K_{t}}\right)$ é uma função de custos de ajustamento, $\operatorname{com} c^{\prime}(\cdot)>0$ e $c^{\prime \prime}(\cdot) \leq 0$.
} 
\& Monacelli 2005, Elekdag et al. 2006). Os principais ajustes que precisam ser realizados no modelo canônico do ponto de vista do presente trabalho referem-se a novas definições do nível geral de preços e inflação, a relação entre as taxas de juros domésticas e internacionais e ao impacto da renda externa sobre o produto doméstico.

Em uma economia aberta, o índice geral de preços depende dos preços de produtos domésticos e importados. Assim, log-linearizando preços domésticos, $P_{H, t}$, em torno do estado estacionário, quando as taxas de câmbio real e nominal são idênticas, obtém-se:

$$
\tilde{p}_{t} \equiv(1-\zeta) \tilde{p}_{H, t}+\zeta \tilde{p}_{F, t}
$$

em que $\zeta$ é a participação dos bens importados no consumo das famílias (grau de abertura comercial) e $P_{F, t}$ representa os preços dos bens importados. Definindo-se os termos de troca internacional como $\widetilde{s}_{t} \equiv \widetilde{p}_{F, t}-\widetilde{p}_{H, t}$, temos a representação para a inflação doméstica ${ }^{11}$ :

$$
\tilde{\pi}_{t} \equiv \tilde{\pi}_{H, t}+\zeta \Delta s_{t}
$$

Por fim, assumindo ainda que o mercado financeiro internacional é completo, obtém-se a representação para a paridade descoberta da taxa de juros, log-linearizada em torno do estado estacionário com condições de perfeita previsibilidade:

$$
\tilde{r}_{t}-\tilde{r}_{t}^{*}=E_{t}\left\{\Delta \tilde{e}_{t}\right\}
$$

em que $\widetilde{r}_{t}^{*}$ é a taxa de juros externa e $E_{t}\left\{\Delta \tilde{e}_{t}\right\}$ é a variação esperada na taxa nominal de câmbio.

Gali \& Monacelli (2005) mostram que a produção na economia aberta de pequeno porte será negativamente relacionada com as taxas de juros domésticas correntes e previstas e com a expectativa de crescimento na produção externa. Os autores indicam que o grau de abertura da economia doméstica influencia a sensibilidade da produção a variações nas taxas de juros e fazem com que a taxa natural de juros dependa do crescimento da produção externa.

A nova curva IS para uma economia aberta de pequeno porte, obtida a partir de uma equação de Euler incorporando hábitos de consumo, custos de ajustamento, regras fiscais, fricções financeiras e log-linearizada em torno do estado estacionário, pode ser representada por:

$$
\begin{aligned}
\tilde{y}_{t}=E_{t} \tilde{y}_{t+1} & -\frac{\epsilon}{\theta}\left(\tilde{r}_{t}-E_{t} \tilde{\pi}_{t+1}\right)+\sum_{i=1}^{I} \tau_{i} \tilde{y}_{t-i}+\mu_{G} \tilde{g}_{t}+\mu_{i} \tilde{i}_{t} \\
& +(1-\epsilon) E_{t}\left\{\Delta \tilde{y}_{t+1}^{*}\right\}+u_{t}^{I S}
\end{aligned}
$$

em que os parâmetros $\tau_{i}$ capturam o grau de persistência decorrente de hábitos de consumo; $\mu_{G}$ representa a elasticidade da produção em relação aos gas-

\footnotetext{
${ }^{11}$ Se a paridade do poder de compra é válida, os termos de troca podem ser redefinidos como $\widetilde{s_{t}} \equiv \widetilde{e_{t}}+\widetilde{p}_{t}^{*}-\widetilde{p}_{H, t}$.
} 
tos do governo ${ }^{12} ; \mu_{I}$ é a elasticidade da produção em relação ao investimento; $\epsilon \equiv 1+\zeta(2-\zeta)(\theta \xi-1)>0$, $\xi$ é a elasticidade de substituição entre bens domésticos e importados ${ }^{13}$; e $\Delta \tilde{y}_{t+1}^{*}$ representa a expectativa de crescimento na produção externa.

O modelo econométrico apresentado na próxima seção tem por objetivo estimar uma curva IS cuja especificação é análoga à equação (20), associada às implicações definidas pelas equações (3), (6), (8), (16), (18) e (19). As seguintes simplificações foram realizadas:

- A equação (20), associada às equações (18) e (19), indicam que a abertura de uma economia afeta a sensibilidade da produção a variações nas taxas de juros e a deixa suscetível a choques externos exógenos. Optou-se por criar um indicador que refletisse a vulnerabilidade externa da economia, que é a variável de interesse deste trabalho.

- A ausência de séries temporais longas para variáveis de expectativas do consumidor e empresas não permitiu avaliar a importância do termo $E_{t} \widetilde{y}_{t+1} 14$.

- Para evitar a perda de graus de liberdade, utilizou-se apenas uma defasagem do componente cíclico do produto como variável explicativa para capturar persistência, embora a metodologia econométrica implique no uso de informação contida em defasagens adicionais, como detalhado na próxima seção.

- A equação (3) se refere à execução da política monetária. Aqui, optou-se por utilizar o componente cíclico do nível de preços como proxy para a efetividade da política monetária em promover a estabilidade dos ciclos econômicos.

- A equação (6) requer que se considere a importância de choques de produtividade, enquanto a equação (8) define ao comportamento cíclico dos gastos do governo.

- Em razão da ausência de dados mensais para o investimento, procurouse incorporar o impacto dos seus principais determinantes à estimativa, conforme definido na equação (17): prêmio de risco, patrimônio líquido e preços de ativos. Mais especificamente, utilizou-se o spread bancário e o valor das empresas comercializadas na bolsa de valores como indicadores desses determinantes.

${ }^{12}$ Fève et al. (2013) utilizam uma função de utilidade log-linear do tipo $u_{t}=\log \left(c_{t}+\alpha_{g} g_{t}\right)-$ $\frac{\eta}{1+v} l_{t}^{1+v}$ e mostram que se $\alpha_{G} \geq 0$, os gastos do governo são substitutos para os gastos do consumo; se $\alpha_{G}<0$, os gastos do governo complementam os gastos de consumo. A elasticidade da produção em relação aos gastos do governo é definida por $\mu_{G} \equiv \frac{\bar{g}}{\bar{y}} \frac{\Delta y}{\Delta g}$, e o multiplicador de gastos no longo prazo é definido por $\frac{\Delta y}{\Delta g}=\frac{1-\alpha_{G}}{1+v\left[1-\frac{\bar{g}}{\bar{y}}\left(1-\alpha_{G}\right)\right]}$.

${ }^{13}$ Gali \& Monacelli (2005) estabelecem que as famílias maximizam a utilidade esperada definida por $E_{0} \sum_{t=0}^{\infty} \beta^{t}\left[U\left(C_{t}\right)-V\left(N_{t}\right)\right]$, onde $V\left(N_{t}\right)$ representa a desutilidade do trabalho, $U\left(C_{t}\right)=$ $\frac{C_{t}^{1-\theta}}{1-\theta}$ e $C_{t}$ é um índice de consumo composto definido por $C_{t}=\left[(1-\zeta)^{\frac{1}{\xi}} C_{H, t}^{\frac{\xi-1}{\xi}}+\zeta^{\frac{1}{\xi}} C_{F, t}^{\frac{\xi-1}{\xi}}\right]^{\frac{\xi}{\xi-1}}$.

${ }^{14}$ Séries temporais mensais de expectativas para o Brasil estão disponíveis apenas a partir de 2001. 
Portanto, para verificar a importância da vulnerabilidade externa para os ciclos econômicos, o modelo empírico descrito na próxima seção estima como o componente cíclico do produto responde a uma maior vulnerabilidade externa e aos desvios das seguintes variáveis em relação às suas tendências de longo prazo: taxa real de juros, produto defasado, gastos do governo, prêmio de risco, preço de ativos, índice geral de preços e produtividade. Com a inclusão da variável dependente defasada como variável explicativa e a potencial endogeneidade das demais variáveis de controle, é necessário o uso do método de variáveis instrumentais, que será detalhado a seguir.

\section{Metodologia Econométrica e Descrição das Variáveis}

O presente estudo foi conduzido utilizando dados mensais da economia brasileira entre janeiro de 1996 e agosto de 2019. Os dados foram obtidos junto ao BCB - Banco Central do Brasil (2016), exceto quando outra fonte for alternativamente mencionada. Esta seção descreve a estratégia econométrica e as variáveis utilizadas no exercício empírico.

\subsection{Metodologia Econométrica}

A equação a ser estimada é definida em sua forma matricial por:

$$
\tilde{y}=X \beta+u
$$

em que $\widetilde{y}$ é uma matriz $\mathrm{n} \times 1$ que representa os desvios do indicador de atividade econômica em relação ao seu estado estacionário, $\mathrm{X}$ é uma matriz $\mathrm{n}$ x $\mathrm{k}$, onde $\mathrm{n}$ é o número de observações temporais e $\mathrm{k}$ é o número de variáveis explicativas; e u é uma matriz n x 1 que representa termo de erro. Foram utilizados os componentes cíclicos de quatro indicadores distintos de atividade econômica, quais sejam o PIB, a produção industrial, o IBC-BR e o emprego $\left(\widetilde{y}=\widetilde{y}_{P I B}, \widetilde{y}_{I N D}, \widetilde{y}_{I B C}\right.$ ou $\left.\widetilde{y}_{E M P}\right)$. Esses componentes cíclicos foram obtidos com o uso de três filtros alternativos comumente utilizados pela literatura para remover as flutuações de baixa frequência de séries temporais. Detalhes dos filtros utilizados encontram-se na próxima subseção.

Exceto pelos choques de produtividade, a estratégia de identificação apresentada na seção anterior implica que parte das variáveis em $X$ são endógenas, ou seja, $E[X / u] \neq 0$. Assim, a matriz $X$ pode ser particionada em $\left[\begin{array}{ll}X_{1} & X_{2}\end{array}\right]$, assumindo que $K_{1}$ variáveis que compõem $X_{1}$ são endógenas e que $K_{2}$ variáveis que compõem $X_{2}$ são exógenas. Logo, a equação (22) pode ser representada por:

$$
\tilde{y}=\left[\begin{array}{ll}
X_{1} & X_{2}
\end{array}\right]\left[\begin{array}{ll}
\beta_{1} & \beta_{2}
\end{array}\right]^{\prime}+u
$$

Logo, as variáveis $K_{1}$ são representadas pelos choques de produtividade $\left(\sigma_{S O L O W}\right)$ e por uma variável dummy utilizada para capturar a mudança de regime cambial ocorrida em 1999 (DFLEX). Já as variáveis em $K_{2}$ são representadas pela variável dependente defasada (L. $\widetilde{y}$, onde L. representa o operador de defasagens), pelo indicador de vulnerabilidade externa e pelos componentes cíclicos do índice de preços, da taxa real de juros, dos gastos do governo, 
de preços de ativos e do prêmio de risco de crédito $\left(f_{E X T}, \widetilde{\pi}, \widetilde{r}, \widetilde{g}, \widetilde{q}\right.$ e $\widetilde{s}$, respectivamente $)^{15}$.

Define-se a matriz de instrumentos como $Z$, com dimensão $\mathrm{n} \times \mathrm{J}$. A matriz $Z$ pode ser particionada em $\left[\begin{array}{ll}Z_{1} & Z_{2}\end{array}\right]$, em que os $L_{1}$ instrumentos em $Z_{1}$ são "instrumentos excluídos" e os $L_{2} \equiv L-L_{1}$ instrumentos em $Z_{2}$ são "instrumentos incluídos" (regressores exógenos; ou seja, $Z_{2} \equiv X_{2}$ ). Como as variáveis em $Z$ são consideradas exógenas, $E(Z \mid u)=0$. Na ausência de heterocedasticidade, o método dos mínimos quadrados em dois estágios (2SLS) é indicado para ser utilizado na estimação; caso contrário, é preferível o uso do método generalizados dos momentos (GMM).

De acordo com Baum et al. (2007), o estimador GMM implica na existência de L momentos representados por:

$$
g_{i}(\beta)=Z_{i}^{\prime} u_{i}=Z_{i}^{\prime}\left(\tilde{y}-X_{i} \beta\right)
$$

em que $g_{i}$ é uma matriz L x 1 e $\mathrm{i}=1,2, \ldots$, n. Para os instrumentos serem exógenos, a seguinte condição deve ser válida: $E\left[g_{i}(\beta)\right]=0$. O estimador GMM identifica o $\beta$ que garante que $\bar{g}(\hat{\beta})=0$, em que $\bar{g}(\hat{\beta})=\frac{1}{n} \sum_{i=1}^{n} g_{i}(\beta)$. Assim, define-se a função critério do GMM por $J(\hat{\beta})=n \bar{g}(\hat{\beta}), W \bar{g}(\hat{\beta})$. O estimador GMM identifica o $\beta$ que minimiza esta função:

$$
\hat{\beta}_{G M M} \equiv \arg \min J(\hat{\beta})=n \bar{g}(\hat{\beta})^{\prime} W \bar{g}(\hat{\beta})
$$

em que $W$ é uma matriz de ponderação L x L. Uma matriz de ponderação ótima é aquela que minimiza a variância do estimador.

No presente estudo, as primeiras duas defasagens em níveis de cada variável endógena foram utilizadas como instrumentos, o que implica que o modelo é sobreidentificado, $\mathrm{J}>\mathrm{K}$. O uso das defasagens como instrumentos é justificada pela estratégia de identificação proposta, já que as variáveis elencadas como explicativas na equação (20) exibem persistência. Logo, para cada variável endógena $X_{2}^{i}$, tem-se como instrumentos suas defasagens $L . X_{2}^{i}$ e $L 2 . X_{2}^{i}$, onde $i=1,2, \ldots, K_{2}$. Como existem mais equações para serem minimizadas do que variáveis desconhecidas, normalmente é impossível identificar um único $\beta$ que garanta que todas as $L$ condições de momento sejam exatamente iguais a zero.

O estimador GMM em dois passos (GMM2S) utiliza os resíduos do primeiro estágio da estimação para definir a matriz de ponderação $\mathrm{W}$ que será utilizada no segundo estágio para estimar $\hat{\beta}_{G M M}$. O estimador GMM2S pressupõe que os erros são possivelmente heterocedásticos, mas sem correlação serial. No entanto, é possível estimar $\mathrm{W}$ assumindo autocorrelação serial, utilizando uma função kernel do tipo Bartlett com bandwidth q definido conforme Newey e West (1987, apud Baum et al. (2007)) ou com base nos dados $\mathrm{da}$ amostra. O presente trabalho estabeleceu $\mathrm{q}=12 \mathrm{em}$ razão dos dados serem mensais, exceto quando a ausência de convergência requeira o uso da definição de q proposta por Newey e West ou $q=n^{1 / 3}$ (Baum et al. 2007).

\footnotetext{
${ }^{15}$ A definição de cada variável será realizada na próxima seção. Assumiu-se, inicialmente, que a vulnerabilidade externa é uma variável endógena, que responde às condições econômicas do país. Posteriormente, as regressões foram reestimadas pressupondo-se que a vulnerabilidade é fruto de choques externos.
} 
Um estimador alternativo ao GMM2S é obtido calculando-se a matriz de ponderação como função de cada valor hipotético de $\beta$ que minimiza a função critério do GMM indicada pela equação (24). Conhecido como estimador continuamente atualizado (continuously updated estimator, GMM-CUE), este estimador permite que a matriz de ponderação $W$ seja modificada enquanto o algoritmo de otimização calcula as derivadas numéricas (Hansen et al. 1996, Chaussé 2010). Ou seja, $\mathrm{W}$ é alterada continuamente à medida em que cada $\hat{\beta}_{G M M}$ é estimado no processo de minimização da função critério do GMM. De acordo com Baum et al. (2007), o GMM-CUE é considerado superior ao GMM2S em amostras finitas e na presença de instrumentos fracos, e será utilizado no presente trabalho para verificar a robustez dos resultados.

$\mathrm{O}$ valor $\mathrm{J}$ da função objetivo avaliada pelo estimador GMM eficiente tem distribuição $\chi^{2} \operatorname{com}(L-K)$ graus de liberdade na hipótese nula de que o conjunto das condições de ortogonalidade dos instrumentos é válido. Esse valor é conhecido com estatística de Sargan-Hansen ou teste das restrições de sobreidentificação. Ademais, os instrumentos escolhidos precisam atender dois critérios:

- As correlações com as variáveis endógenas devem ser diferentes de zero; caso contrário, diz-se que o modelo é subidentificado ou não identificado;

- As correlações devem ser representativas; caso contrário, diz-se que a identificação é fraca.

Um modelo que é subidentificado implica na existência de vieses na estimação dos coeficientes, com sérios problemas em amostras finitas. Alguns testes estão disponíveis para verificar se o modelo é subidentificado. Rejeitar a hipótese nula desses testes indica que o modelo é identificado. O presente trabalho utiliza a estatística de Kleibergen e Paap (2006, apud Baum et al. (2007)), que é robusta para a presença de autocorrelação e heterocedasticidade.

Nesse mesmo contexto de subidentificação, é possível testar se um subconjunto dos instrumentos é redundante. De acordo com Baum et al. (2007), o uso de um número elevado de instrumentos ou condições de momento afeta negativamente o desempenho do estimador GMM em amostras finitas. Por essa razão, procurou-se limitar o número de defasagens das variáveis endógenas utilizadas como instrumentos e testes de redundância foram realizados.

Por fim, dificuldades também surgem se as correlações entre os instrumentos e as variáveis endógenas forem diferentes de zero, mas não significativas. O teste de instrumentos fracos proposto por Stock e Yogo (2005, apud Baum et al. (2007)), que pressupõe que os erros são identicamente e independentemente distribuídos, verifica dois aspectos: viés relativo máximo em relação a MQO e tamanho máximo. Rejeição da hipótese nula significa ausência do problema de instrumentos fracos. Na presença de autocorrelação e heterocedasticidade, Baum et al. (2007) sugerem o uso da regra que a estatística $\mathrm{F}$ calculada seja maior do que 10 para excluir a hipótese de instrumentos fracos, conforme proposto por Staiger \& Stock (1997). É sabido que a estimação de equações de Euler para consumo e produção podem sofrer com o problema de instrumentos fracos, por isso a importância que os métodos de inferência sejam robustos neste aspecto (Ascari et al. 2019).

\subsection{Descrição das Variáveis}

As variáveis foram agrupadas em três categorias: os componentes cíclicos dos indicadores de atividade econômica; as variáveis utilizadas na composição do 
índice de vulnerabilidade externa; e as variáveis de controle que, juntamente com o indicador de vulnerabilidade externa, têm o potencial de afetar as flutuações econômicas de curto prazo.

Como indicado anteriormente, quatro variáveis foram utilizadas como indicadores de atividade econômica: o valor real do produto interno bruto (PIB), o índice de produção industrial (IND), o IBC-BR (IBC) e o nível de emprego (EMP). Para obter os componentes cíclicos, calculou-se o logaritmo natural dos dados dessazonalizados dessas séries temporais e, posteriormente, utilizouse três filtros alternativos para remover flutuações de baixa frequência.

Inicialmente, utilizou-se o filtro HP two-sided, tradicionalmente utilizado pela literatura (Hodrick \& Prescott 1997) ${ }^{16}$. O uso desse filtro é criticado por gerar relações dinâmicas espúrias e introduzir distorções nas primeiras e últimas observações dos componentes cíclicos derivados (Hamilton 2018). Assim, utilizou-se também o filtro HP one-sided, que é considerado mais apropriado aos modelos DSGE e que reduz o problema de previsibilidade espúria associado ao filtro HP two-sided. Por fim, utilizou-se o filtro band-pass proposto por Christiano \& Fitzgerald (2003), que é mais eficiente que o filtro HP e não gera a perda em graus de liberdade associada ao uso dos filtros band-pass de maior precisão (Baxter \& King 1999, Hamilton 2018).

\section{Indicador de Vulnerabilidade Externa}

É possível definir a vulnerabilidade externa em termos do grau de exposição de um país a choques externos e da sua capacidade de recuperação. Para Ribeiro (2016), a fragilidade de fundamentos macroeconômicos e limitações institucionais e estruturais são os principais elementos que contribuem para uma maior suscetibilidade de um país a choques externos.

O presente trabalho relaciona-se à literatura que procura identificar preditores de crises externas (Kaminsky et al. 1998, IMF - International Moneraty Fund 2000, Dabla-Norris \& Gündüz 2014, Scheubel et al. 2019). Esses trabalhos envolvem a análise de economias emergentes e utilizam metodologias diversas para derivar índices de vulnerabilidade, que levam em consideração o grau de exposição de empresas e do setor financeiro, o perfil de endividamento externo do governo, a eficácia das políticas macroeconômicas e aspectos de liquidez e solvência do balanço de pagamentos. Essa literatura serviu de guia na seleção de variáveis utilizadas para a derivação do índice de vulnerabilidade externa para o Brasil.

O presente trabalho inova ao utilizar o modelo de fator dinâmico para a derivação do indicador de vulnerabilidade externa e ao estabelecer a importância deste indicador para o desempenho macroeconômico de curto prazo com o uso de uma estratégia de identificação fundamentada teoricamente e de metodologia econométrica alternativa aos modelos VAR mais comumente utilizados. Como o modelo de fator dinâmico pode apresentar problemas de convergência com o uso de um número muito elevado de variáveis, foi necessário selecionar as mais representativas, utilizando as indicações em IMF International Moneraty Fund (2000) e Ribeiro (2016) como referências principais.

Treze variáveis foram selecionadas para compor o indicador de vulnerabilidade externa da economia brasileira. Essas variáveis relacionam-se ao grau

\footnotetext{
${ }^{16}$ Como foram utilizados dados mensais, definiu-se o parâmetro de suavização do filtro HP como igual a 129.600, conforme indicado por Ravn \& Uhlig (2002).
} 
de abertura comercial, à volatilidade das taxas de câmbio, à adequação de reservas cambiais, à sustentabilidade do endividamento externo e ao fluxo de capitais externos. As variáveis capturam, portanto, não somente aspectos estruturais relacionados à economia doméstica, mas também os três canais de transmissão de choques externos identificados pela literatura e discutidos na seção 2 deste trabalho: o canal do comércio, o canal financeiro e o canal da incerteza.

ABERTURA mede o grau de inserção do país no comércio mundial. A variável foi obtida adicionando-se os percentuais das exportações e das importações em relação ao PIB do país. O efeito desse indicador para a estabilidade econômica é ambíguo: uma maior abertura comercial pode tornar o país mais suscetível aos choques externos, mas também facilita o ajuste de choques domésticos por meio das exportações (Loayza \& Raddatz 2007, Montalbano 2011).

A volatilidade cambial foi medida pela volatilidade da taxa de câmbio real (VOLCAMBREAL), expressa em relação ao dólar americano. A volatilidade das taxas de câmbio distorce preços relativos, afeta negativamente o comércio externo e desestimula as transações financeiras no mercado internacional, pois eleva a incerteza e compromete a alocação ótima de recursos (Tenreyro 2007, Aghion et al. 2009, Kaltenbrunner \& Painceira 2014). VOLCAMBREAL foi calculada conforme indicado por Moslares \& Ekanayake (2018):

$$
\operatorname{VOLCAMBREA} L_{t}=\left[\frac{1}{m} \sum_{i=1}^{m}\left(\ln R E R_{t+i-1}-\ln R E R_{t+i-2}\right)^{2}\right]^{0,5}
$$

em que RER é o índice do câmbio real e efetivo e $\mathrm{m}=12$.

A acumulação de reservas cambiais permite à economia manter a liquidez e absorver choques externos de maneira mais suave, particularmente quando o acesso a recursos no mercado internacional é limitado. Três variáveis foram utilizadas para representar o grau de adequação das reservas, com valores maiores dessas variáveis indicando uma menor vulnerabilidade externa (IMF - International Moneraty Fund 2000):

- RESIMP indica a razão entre o volume de reservas cambiais acumuladas nos últimos 12 meses e o saldo de importações acumulado em igual período. Trata-se de um indicador de adequação de reservas para países com acesso restrito ao mercado de capitais internacional.

- RESM2 mede a razão entre o volume de reservas externas acumuladas nos últimos 12 meses e o saldo acumulado em igual período dos meios de pagamentos ampliados medidos por $\mathrm{M} 2{ }^{17}$. Quando o estoque de moeda cresce em relação às reservas e este indicador diminui, maior o risco potencial de fuga de capitais ${ }^{18}$.

- RESPIB mede a razão entre o volume de reservas cambiais acumuladas nos últimos 12 meses e o PIB mensal acumulado em igual período. Essa variável mede nível de acumulação de reservas em relação ao tamanho da economia.

\footnotetext{
${ }^{17} \mathrm{M} 2$ inclui moeda em circulação, depósitos à vista, depósitos especiais remunerados, poupança, títulos emitidos por instituição depositárias.

${ }^{18} \mathrm{Em}$ países desenvolvidos, onde a incerteza é baixa e, consequentemente, a demanda por moeda é elevada, este indicador é relativamente baixo.
} 
A captação externa de recursos contribui para amenizar choques externos, mas pode gerar maior vulnerabilidade se utilizada de maneira excessiva. Os seguintes indicadores de sustentabilidade do endividamento foram incluídos:

- EMPTOTEXP representa a razão entre o saldo do endividamento externo total líquido acumulado nos últimos 12 meses e o saldo de exportações acumulado em igual período. Um valor elevado para essa variável indica uma menor capacidade de pagamento do endividamento ou um ônus significativo com serviço da dívida (IMF - International Moneraty Fund 2000).

- EMPTOTPIB relaciona o endividamento com a base de recursos de um país, ou seja, indica a capacidade de direcionar a produção para a exportação e melhorar a capacidade de pagamento do país. A variável é medida com a razão entre o saldo do endividamento externo total líquido acumulado nos últimos 12 meses e o PIB acumulado em igual período.

- TXROLTOT representa a taxa de rolagem da dívida total, calculada pelo quociente entre o fluxo de desembolsos e as amortizações de títulos e empréstimos diretos tomados por residentes junto a não residentes em um dado período. Uma taxa de rolagem acima de $100 \%$ significa que a absorção de recursos externos foi suficiente para cobrir o vencimento dos compromissos externos.

Foram incorporadas três medidas de taxas de juros internacionais no cálculo do indicador de vulnerabilidade externa: o logaritmo natural do Emerging Market Bond Index Plus (LNEMBI) obtido junto ao IPEA - Instituto de Pesquisa Econômica Aplicada (2020) e as taxas Libor de curto (LIBOR3M) e longo prazo (LIBOR12M) obtidas em FRB - Federal Reserve Bank of ST $(2020)^{19}$. O EMBI é um índice que mede a diferença entre os retornos financeiros obtidos em uma carteira selecionada de títulos do país e a taxa de retorno dos títulos emitidos pelo Tesouro americano. Já a taxa Libor é a taxa de juros média utilizada pelas principais instituições bancárias para empréstimos de recursos aos demais bancos no mercado de Londres, sendo considerada uma referência das taxas de juros no mercado internacional.

Uma elevação nas taxas de juros internacionais pode ser resultado de um aumento na demanda por crédito ou da deterioração nos termos de acesso a este mercado. Reyes-Heroles \& Tenorio (2017) mostram que uma elevação nas taxas de juros internacionais é normalmente acompanhada por um aumento persistente na volatilidade dessas taxas, o que eleva a incerteza e pode tornar o mercado internacional de crédito inacessível.

Por fim, foram incluídas outras duas rubricas do balanço de pagamentos que também afetam o grau de vulnerabilidade externa de um país: investimentos diretos líquidos e investimentos em carteira (INVDIRPIB e INVCARTPIB, respectivamente $)^{20}$. A relação entre essas variáveis e a vulnerabilidade externa é a priori ambígua.

O investimento direto é relativamente estável e uma fonte de financiamento mais sustentável para os déficits em transações correntes do que o investimento em carteira, que exibe elevada volatilidade (Frankel \& Saravelos 2012, Kaltenbrunner \& Painceira 2014, Rohn et al. 2015). Assim, um aumento no volume de investimentos diretos é normalmente associado a períodos de

\footnotetext{
${ }^{19}$ A LIBOR3M e a LIBOR12M representam a média mensal da Libor diária para títulos com vencimento no horizonte de três e 12 meses, respectivamente.

${ }^{20}$ As duas variáveis representam os saldos acumulados nos últimos 12 meses como razão do PIB acumulado em igual período.
} 
estabilidade, enquanto a presença mais significativa de investimentos em carteira pode ser desestabilizadora.

\section{Modelo de Fator Dinâmico}

A análise de fatores permite identificar motivações latentes para o comportamento correlacionado de um conjunto de variáveis. Utilizar a análise de fatores para derivar o indicador de vulnerabilidade externa baseia-se no pressuposto que escolhas de políticas econômicas ou mudanças de preferências de investidores podem afetar o ajuste das contas externas de um país. Além de deixar o país mais suscetível a choques internacionais, a vulnerabilidade externa também pode funcionar como um gatilho para a ocorrência de uma crise econômica mais generalizada ${ }^{21}$.

A análise de fatores multivariada não pode ser utilizada quando os fatores seguem um processo que se modifica ao longo do tempo. No caso de séries temporais que apresentam componentes autorregressivos, sugere-se o uso do modelo de fator dinâmico (ver Geweke (1977); e Stock \& Watson (2011)).

A premissa deste modelo é que o movimento sincronizado de um vetor de séries temporais com elevada dimensão $\left(X_{t}\right)$ é gerado por um conjunto de poucos fatores latentes $\left(f_{t}\right)$ e um vetor de erros idiossincráticos com média zero $\left(e_{t}\right)$. Presume-se que o vetor de fatores latentes segue um processo de séries temporais descrito por um vetor autorregressivo. Stock \& Watson (2011) definem:

$$
\begin{gathered}
X_{t}=\lambda(L) f_{t}+e_{t} \\
f_{t}=\psi(L) f_{t-1}+\eta_{t}
\end{gathered}
$$

onde $X_{t}$ e $e_{t}$ possuem dimensão $\mathrm{N}$ x 1 , $\mathrm{N}$ é o número de variáveis. Existe um número q de fatores dinâmicos de forma que $f_{t}$ e $\eta_{t}$ possuem dimensão $\mathrm{q} \times 1$. L é o operador de defasagem e as matrizes polinomiais defasadas $\lambda(L)$ e $\psi(L)$ possuem dimensões $\mathrm{N}$ x q e q x q, respectivamente. Cada polinomial defasado "i", $\lambda_{i}(L)$, é chamado de carga do fator dinâmico para a variável $X_{i, t}$.

Os parâmetros são estimados utilizando máxima verossimilhança com base em um filtro de Kalman. Foi possível utilizar esta estratégia porque o número de séries temporais é restrito em relação ao número de observações. Assim como em Quah e Sargent (1993, apud Stock \& Watson (2011)) e Aruoba et al (2009, apud Stock \& Watson (2011)), derivou-se um único fator dinâmico. Assumiu-se que as variáveis originais são estacionárias em primeiras diferenças, exceto VOLCAMBREAL, que foi considerada estacionária em ní$\mathrm{vel}^{22}$. Ademais, pressupôs-se que o fator latente segue um processo autorregressivo de segunda ordem.

Os resultados obtidos com a estimação do modelo de fator dinâmico estão apresentados na Tabela 1. O teste de Wald indica a significância conjunta das

\footnotetext{
${ }^{21}$ A crise do México em 1994 e dos países asiáticos em 1997 são exemplos de processos recessivos cuja origem é frequentemente associada a desequilíbrios no balanço de pagamento e a políticas cambiais inapropriadas.

${ }^{22}$ Esses pressupostos lastrearam-se em testes de raiz unitária apresentados no Apêndice Apêndice $\mathrm{A}$.
} 
variáveis inclusas no modelo. As primeiras e segundas defasagens do fator são estatisticamente significantes nos níveis convencionais, o que indica que o fator é persistente.

$\mathrm{O}$ fator mostrou-se um bom previsor para as seguintes variáveis: VOLCAMBREAL, EMPTOTPIB, EMPTOTEXP, LNEMBI, INVCARPIB, RESM2, RESIMP e RESPIB. De forma geral, os coeficientes indicam que uma elevação no fator é associada a um aumento na vulnerabilidade externa. Ressalta-se, contudo, que VOLCAMBREAL mostrou-se negativamente relacionada com o fator.

Tabela 1: Modelo de Fator Dinâmico: Vulnerabilidade Externa

\begin{tabular}{|c|c|c|c|c|c|c|}
\hline & Coeficiente & $\begin{array}{l}\text { Desv. } \\
\text { Pad. }\end{array}$ & $\mathrm{Z}$ & $P>|x|$ & \multicolumn{2}{|c|}{$\begin{array}{c}95 \% \text { Intervalo } \\
\text { Confiança }\end{array}$} \\
\hline Fator & & & & & & \\
\hline L1 & $0,176^{* * *}$ & 0,060 & 2,95 & 0,003 & 0,059 & 0,294 \\
\hline L2 & $0,110^{*}$ & 0,060 & 1,84 & 0,066 & $-0,007$ & 0,228 \\
\hline volcambreal & $-0,006^{* *}$ & 0,002 & $-2,41$ & 0,016 & $-0,010$ & $-0,001$ \\
\hline D.emptotpib & $0,002^{* * *}$ & 0,000 & 8,70 & 0,000 & 0,002 & 0,003 \\
\hline D.emptotexp & $0,021^{* * *}$ & 0,002 & 9,24 & 0,000 & 0,016 & 0,025 \\
\hline D.txroltot & $-1,805$ & 1,254 & $-1,44$ & 0,150 & $-4,262$ & 0,652 \\
\hline D.libor3m & 0,018 & 0,012 & 1,53 & 0,126 & $-0,005$ & 0,041 \\
\hline D.libor12m & 0,011 & 0,012 & 0,92 & 0,356 & $-0,012$ & 0,034 \\
\hline D.lnembi & $0,023^{* * *}$ & 0,007 & 3,48 & 0,000 & 0,010 & 0,036 \\
\hline D.resm2 & $-0,012^{* * *}$ & 0,001 & $-12,32$ & 0,000 & $-0,014$ & $-0,010$ \\
\hline D.resimp & $-0,037^{* * *}$ & 0,002 & $-21,17$ & 0,000 & $-0,040$ & $-0,034$ \\
\hline D.respib & $-0,004^{* * *}$ & 0,0002 & $-22,63$ & 0,000 & $-0,004$ & $-0,003$ \\
\hline D.invdirpib & 0,0001 & 0,000 & 0,77 & 0,440 & 0,000 & 0,000 \\
\hline D.invcartpib & $0,001^{* * *}$ & 0,000 & 5,50 & 0,000 & 0,001 & 0,001 \\
\hline D.abertura & 0,0002 & 0,000 & 1,29 & 0,196 & 0,000 & 0,001 \\
\hline No. Obs. & 287 & & & & & \\
\hline Wald $\chi^{2}$ & 560,85 & Prob. & 0,000 & & & \\
\hline
\end{tabular}

Fonte: elaboração própria.

Na Figura 1, é possível observar o comportamento do fator estimado durante o período em análise e comparar seu desempenho com o índice VIX ${ }^{23}$. Recessões são indicadas pelas faixas sombreadas, utilizando a datação dos ciclos econômicos disponibilizada pelo CODACE - Comitê de Datação dos Ciclos Econômicos (2016). O fator exibe elevada variância, em razão de maior parte das variáveis originais serem incluídas em primeiras diferenças. Preliminarmente, observa-se que o indicador de vulnerabilidade externa tende a aumentar em processos recessivos causados particularmente por choques externos (crises asiática e Russa em 1998; a Grande Recessão de 2008 e 2009). Nesses períodos, seu comportamento se assemelha àquele também apresentado pelo índice VIX. Resultados da análise formal de sua relação com a volatilidade dos ciclos econômicos no Brasil serão apresentados na seção 5.

\footnotetext{
${ }^{23} \mathrm{O}$ índice VIX mede a expectativa de volatilidade dos preços das 500 ações mais transacionadas na bolsa de valores americana para os próximos 30 dias. O VIX constitui um indicador risco de mercado e pode ser utilizado como proxy para a instabilidade externa. Os dados foram obtidos em CBOE - Chicago Board of Exchange (2016).
} 


\subsection{Variáveis de Controle}

Além da vulnerabilidade externa representada pelo fator estimado na subseção anterior $\left(f_{E X T}\right)$ e da variável dependente defasada (L. $\left.\widetilde{y}\right)$ que captura persistência, a estimativa da equação (21) inclui como variáveis de controle os componentes cíclicos das seguintes variáveis: índice de preços, taxa real de juros, gastos do governo, preços de ativos, prêmio de risco de crédito e resíduo de Solow.

Figura 1: Indicador de Fragilidade Externa

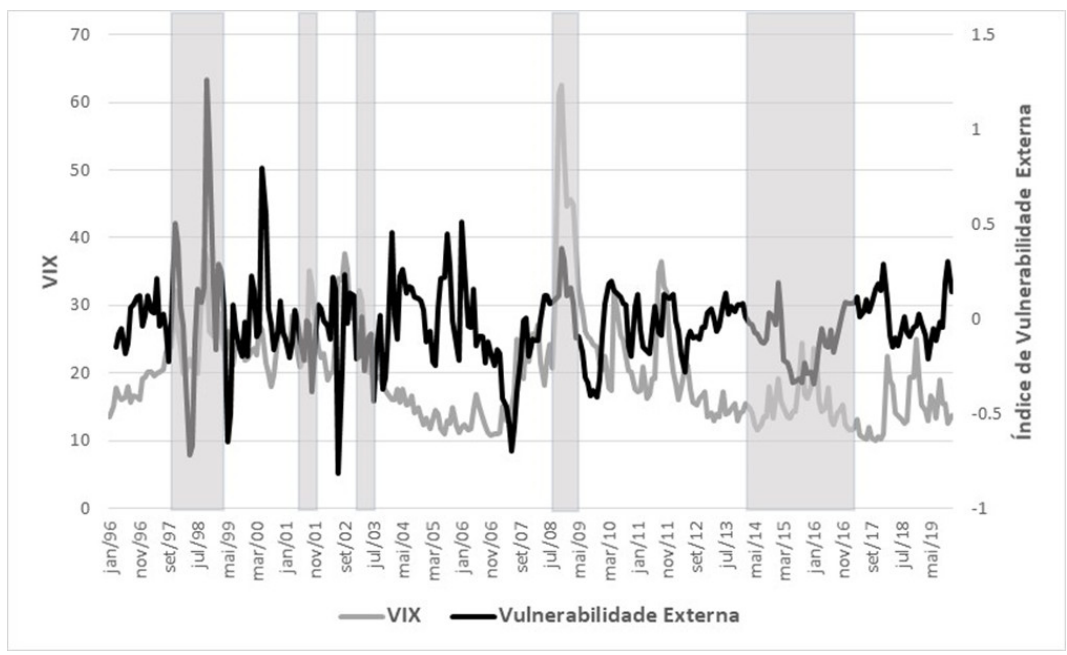

Fonte: elaboração própria.

O componente cíclico do índice de preços $(\widetilde{\pi})$ foi obtido a partir do logaritmo do Índice de Preços ao Consumidor ampliado. Como apontado anteriormente, este indicador é comumente utilizado na literatura como indicador da efetividade da política monetária em promover estabilidade macroeconômica (Backus et al. 1992, Karras \& Song 1996). Para o cálculo do componente ć́clico da taxa real de juros $(\widehat{r})$, utilizou-se a taxa real efetiva, calculada a partir da diferença entre taxa Selic e a taxa de inflação medida a partir do IPCA, ambas anualizadas no mês.

Como indicador de deterioração das condições de crédito e medida do prêmio de risco, utilizou-se o spread bancário, medido a partir da diferença entre a taxa média de juros em créditos concedidos a pessoas jurídicas e a taxa Selic, ambas anualizadas no mês. Um aumento no componente cíclico do spread bancário $(\widetilde{s})$ reflete um agravamento na assimetria de informação, elevando o prêmio com financiamento utilizando recursos externos à firma.

As flutuações cíclicas nos preços de ativos $(\widetilde{q})$ foram mensuradas com base no valor das empresas cujas ações são transacionadas na bolsa de valores em relação ao PIB. Esta variável, conhecida como o indicador de Buffett, é frequentemente utilizada para verificar a existência de bolhas no mercado de ativos.

A conduta da política fiscal foi medida pelo componente cíclico dos gastos do governo em proporção ao PIB $(\widetilde{g})$. Uma relação inversa entre gastos do governo e indicadores de volatilidade macroeconômica sinaliza que a política fiscal é utilizada de maneira contracíclica. Caso contrário, a política fis- 
cal seria pró-cíclica, resultado particularmente comum em países emergentes (Kaminsky et al. 1998, Alesina \& Tabellini 2005).

Já o componente cíclico do resíduo de Solow $(\widetilde{a})$ foi empregado para capturar o impacto de choques de produtividade na economia, associados não somente a inovações tecnológicas, mas a mudanças na eficiência produtiva. $\mathrm{O}$ resíduo é obtido pela diferença entre a variação no logaritmo da produção em dois períodos consecutivos e o produto de $(1-\alpha)$ pela variação no logaritmo do emprego, com $\alpha=0,36$, conforme proposto por Backus et al. (1992) e Karras \& Song (1996).

Por fim, foi incorporada uma variável dummy à análise para identificar a reforma macroeconômica de 1999. Como forma de lidar com a crise do balanço de pagamentos ocorrida no final dos anos 90, o regime de bandas cambiais foi abandonado em janeiro de 1999. Desde então, adotam-se taxas de câmbio flutuantes, com o Banco Central intervindo quando ocorrem processos severos de apreciação ou depreciação cambial. Criou-se a variável DFLEX, atribuindo-lhe o valor zero até dezembro de 1998 e a unidade para o período posterior.

As estatísticas descritivas e correlações cruzadas das variáveis incluídas no estudo encontram-se no Apêndice Apêndice $\mathrm{B}^{24}$. A avaliação preliminar dos dados indica que a maior parte dos regressores exibe correlação contemporânea com os componentes cíclicos da produção. Conclusões mais robustas sobre a relação entre as variáveis devem ser extraídas da estimação dos modelos econométricos, cujos resultados são apresentados na seção 5 .

\section{Resultados da Análise Econométrica}

As estimações foram realizadas utilizando inicialmente as variáveis cíclicas obtidas com o filtro HP e, posteriormente, com os componentes cíclicos obtidos com o filtro CF. Utilizou-se o GMM2S e CUE sempre que a presença de heterocedasticidade foi identificada; caso contrário, as estimações foram conduzidas por 2SLS. Para verificar a robustez dos resultados, os testes usuais de especificação foram realizados ${ }^{25}$. Por fim, testou-se a possibilidade de o indicador de vulnerabilidade externa ser uma variável exógena, já que a Figura 1 aparenta indicar que esta variável é particularmente sensível a choques externos.

Na Tabela 2, são apresentados os resultados com variáveis cíclicas obtidas com o filtro HP. Quase todas as estimações foram conduzidas levando em consideração a presença de autocorrelação e heterocedasticidade dos resíduos. Entretanto, nas estimativas em que os componentes cíclicos do IBC e da produção industrial foram utilizados como variáveis dependentes, a ausência de heterocedasticidade indicou o uso do estimador de 2SLS com correção para autocorrelação.

Observa-se que a vulnerabilidade externa é positivamente relacionada com os componentes cíclicos da produção e emprego, embora esse resultado somente seja estatisticamente relevante em duas estimações, ambas realizadas com o uso do filtro HP two-sided. Os resultados mostram também que o im-

\footnotetext{
${ }^{24}$ Foram apresentadas as estatísticas descritivas para as estimações que utilizaram o filtro HP One-Sided e o filtro CF. Resultados para o filtro HP Two-Sided são semelhantes e podem ser solicitados aos autores.

${ }^{25}$ Os resultados dos testes de especificação encontram-se no Apêndice Apêndice C.
} 
pacto econômico da vulnerabilidade externa pode não ser expressivo no Brasil: considerando os valores medianos das variáveis, um aumento de $10 \%$ em $f_{E X T}$ elevaria $\widetilde{y}_{P I B}$ em $0,9 \%$ e $\widetilde{y}_{E M P}$ em $1,3 \%$, ceteris paribus (estimações II e V, respectivamente). A relação positiva entre vulnerabilidade externa e atividade econômica já havia sido documentada por Gourinchas \& Obstfeld (2012) e Shin (2016), que mostram que uma rápida elevação no endividamento e apreciação cambial durante expansões constituem indicadores de vulnerabilidade financeira e crise, particularmente em economias emergentes.

Exceto pela inflação e gastos do governo, as demais variáveis indicam, de maneira geral, resultados estatisticamente significantes e condizentes com a literatura. Os choques de produtividade representados pelo resíduo de Solow têm um impacto positivo sobre o componente cíclico da produção, independente de se utilizar o PIB, a produção industrial ou o IBC como indicadores. Os coeficientes de $\widetilde{a}$ são estatisticamente significantes e economicamente relevantes em nove das doze estimações. Não obstante, choques positivos de produtividade reduzem o emprego, resultado que é consistente com modelos teóricos que pressupõem concorrência monopolística e rigidez nominal (e.g. Gali (1999)).

A taxa real de juros se relaciona negativamente com o emprego e com a produção, e esse resultado é estatisticamente significante em oito das doze estimativas. Kanczuk (2004) indica que essa relação robusta entre taxa real de juros, produção e emprego é fruto de uma característica peculiar da economia brasileira. Para o autor, a taxa real de juros no Brasil é fortemente determinada pela condução da política fiscal. Choques positivos na taxa de juros funcionam como choques negativos de produtividade, quando existem restrições de capital de giro por parte das firmas. Elevações nas taxas reais de juros provocam um efeito de "crowding out" do capital produtivo em razão do endividamento governamental, afetando negativamente a produção e o mercado de trabalho.

Já os preços de ativos relacionam-se de maneira estatisticamente significante com o emprego e com a produção - em especial com o indicador de produção industrial e com o IBC - em sete das doze estimações. Como estabelecido pelo modelo teórico, elevações no patrimônio líquido reduzem a assimetria de informação e levam a aumentos na produção. No entanto, aumentos nos preços dos ativos se relacionam negativamente com o emprego, resultado que possivelmente revela a importância do efeito riqueza para a dinâmica do mercado de trabalho (Kanczuk 2004).

O spread bancário mostrou-se contracíclico, com elevações no prêmio de risco contribuindo para o declínio na produção, um resultado consistente com modelos teóricos que pressupõem a existência de assimetria de informação (e.g. Bernanke et al. (1998)). No entanto, ao contrário do previsto pela literatura, o spread mostrou-se positivamente relacionado com o componente cíclico do emprego, embora a pequena magnitude do seu coeficiente indique a pouca relevância econômica deste resultado.

Como apontado anteriormente, o filtro HP é considerado menos eficiente do que os filtros do tipo band-pass. Ademais, observou-se que apenas quatro das doze estimações utilizando o filtro HP são robustas ao teste de identificação fraca (Tabela C.1 no Apêndice Apêndice C). A estatística F do teste de Kleibergen-Paap Wald somente situou-se acima de 10, como proposto por Staiger \& Stock (1997), nas estimações cujos componentes cíclicos fizeram uso do HP one-sided e que definiram o PIB e o emprego como medidas de desempe- 
Tabela 2: Estimações com o uso do Filtro HP

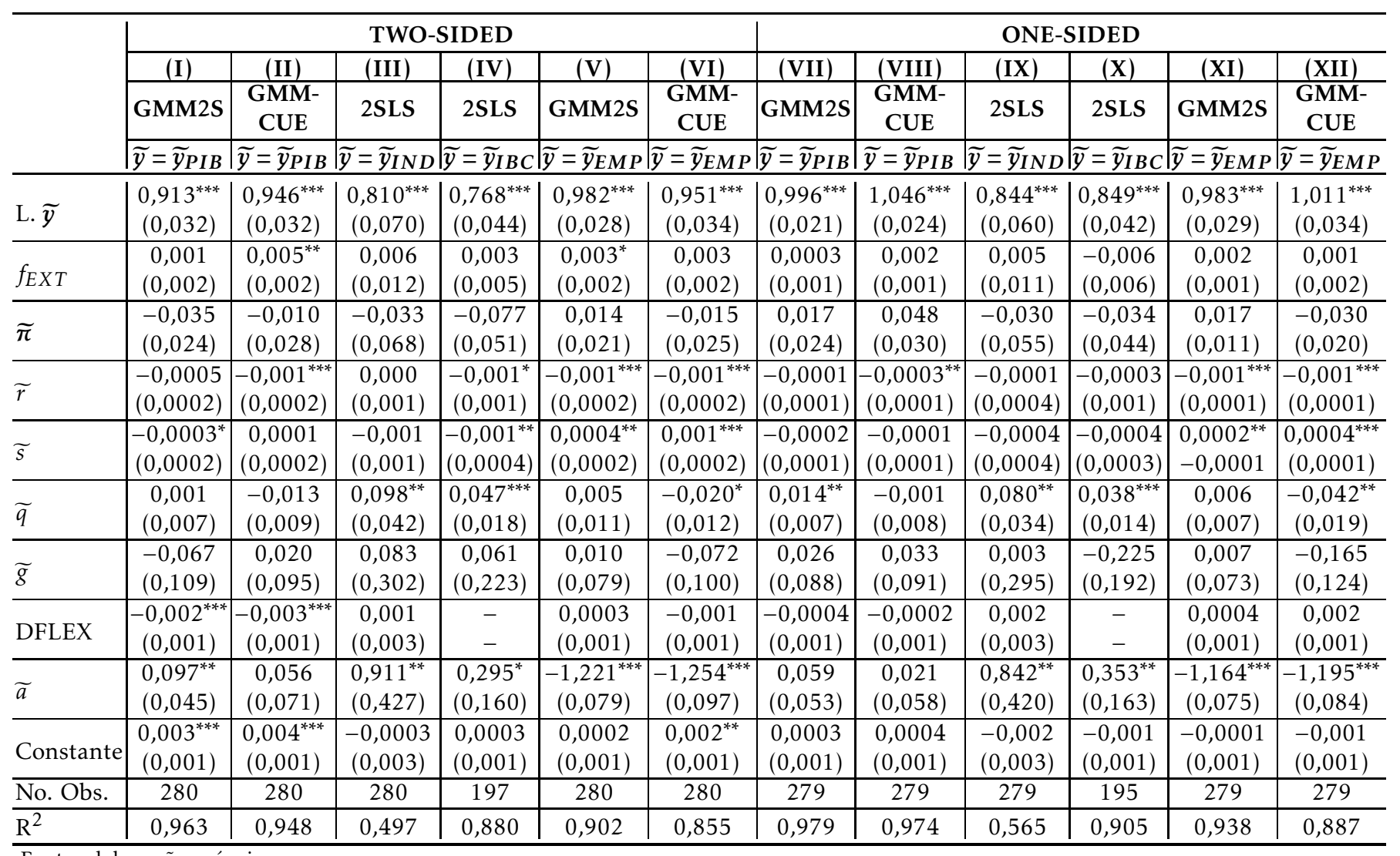

Notas: erros robustos em parêntesis, ${ }^{* * *} \mathrm{p}<0,01,{ }^{* *} \mathrm{p}<0,05 \mathrm{e}^{*} \mathrm{p}<0,10$ 
nho macroeconômico.

Assim, novas estimações foram conduzidas utilizando o filtro CF para obter os componentes cíclicos das variáveis. Os testes de especificação das estimativas com o filtro CF mostraram-se satisfatórios, exceto pela presença de subidentificação em três dos oito modelos estimados (Tabela C.2 no Apêndice Apêndice $\mathrm{C}$ ). As estimações que fizeram uso de variáveis cíclicas obtidas com o filtro $\mathrm{CF}$ indicam que vários dos resultados descritos anteriormente mantiveram-se inalterados, mas o indicador de vulnerabilidade externa passou a apresentar significância estatística de maneira mais consistente (Tabela 3).

Expansões de curto prazo na atividade econômica são associadas a aumentos na vulnerabilidade externa: o coeficiente de $f_{E X T}$ manteve-se positivo e apresentou significância estatística em cinco dos oito modelos estimados com o uso do filtro CF. Não obstante, a relevância econômica da vulnerabilidade externa para o desempenho macroeconômico de curto prazo permaneceu pouco representativa: um aumento de $10 \%$ no indicador de vulnerabilidade leva a um aumento de $0,3 \%$ em $\widetilde{y}_{P I B}, 0,4 \%$ em $\widetilde{y}_{I N D}, 0,7 \%$ em $\widetilde{y}_{I B C}$, e $0,8 \%$ em $\widetilde{y}_{E M P}$, ceteris paribus (estimações I, III, VI e VII, respectivamente).

Dentre os demais fatores que influenciam os ciclos econômicos, destacaramse novamente a taxa real de juros e os preços dos ativos. A taxa real de juros é negativamente relacionada com os componentes cíclicos do IBC, da produção industrial e do emprego, mas mostra-se positivamente relacionada com o componente cíclico do PIB. A relação com o PIB, embora estatisticamente significativa, não é relevante economicamente, já que a magnitude do coeficiente é reduzida.

Elevações nos preços dos ativos contribuem para a expansão na atividade econômica, um resultado economicamente relevante e estatisticamente significante em cinco das oito estimações. Essa relação entre preços de ativos e desempenho macroeconômico é a esperada pelo modelo teórico apresentado anteriormente. Os resultados para as outras variáveis explicativas são menos consistentes, apresentando significância estatística em menos da metade das estimações.

Como indicado anteriormente, conjecturou-se que o caráter pró-cíclico da vulnerabilidade externa pode ser fruto da elevação no endividamento e apreciação cambial durante expansões. Para verificar a plausibilidade desta hipótese, os modelos foram reestimados utilizando os componentes cíclicos da taxa de câmbio e do endividamento externo em relação ao PIB em substituição à $f_{E X T}$. Considerando os resultados estatisticamente significantes apresentados na Tabela 4, observa-se que a apreciação cambial e o aumento do endividamento estão associados à expansão na atividade econômica, embora o desempenho do endividamento seja sensível ao indicador de atividade econômica utilizado. A apreciação cambial é associada a um aumento no componente cíclico do PIB, da produção industrial e do IBC, mas a uma redução no componente cíclico do emprego. Já o endividamento tende a crescer durante expansões, exceto quando se utiliza o componente cíclico do PIB com variável dependente.

Como última verificação de robustez dos resultados, estimaram-se os modelos com base no pressuposto que a vulnerabilidade externa é uma variável exógena. A plausibilidade deste pressuposto é ratificada pelos Testes $\mathrm{C}$ apresentados na Tabela 4, que indicaram não ser possível rejeitar a hipótese nula de exogeneidade de $f_{E X T}$ (Baum et al. 2007). Ainda na Tabela 4, os resultados 
Tabela 3: Estimações com o Uso do Filtro CF

\begin{tabular}{|c|c|c|c|c|c|c|c|c|}
\hline & (I) & (II) & (III) & (IV) & (V) & (VI) & (VII) & (VIII) \\
\hline & GMM2S & $\begin{array}{l}\text { GMM- } \\
\text { CUE }\end{array}$ & GMM2S & $\begin{array}{l}\text { GMM- } \\
\text { CUE }\end{array}$ & GMM2S & $\begin{array}{l}\text { GMM- } \\
\text { CUE }\end{array}$ & GMM2S & $\begin{array}{l}\text { GMM- } \\
\text { CUE }\end{array}$ \\
\hline & $\widetilde{y}=\widetilde{y}_{P I B}$ & $\widetilde{y}=\widetilde{y}_{P I B}$ & $\widetilde{y}=\widetilde{y}_{I N D}$ & $\widetilde{y}=\widetilde{y}_{I N D}$ & $\widetilde{y}=\widetilde{y}_{I B C}$ & $\widetilde{y}=\widetilde{y}_{I B C}$ & $\widetilde{y}=\widetilde{y}_{E M P}$ & $\widetilde{y}=\widetilde{y}_{E M P}$ \\
\hline L. $\widetilde{y}$ & $\begin{array}{c}0,905^{* * *} \\
(0,014)\end{array}$ & $\begin{array}{c}0,387 \\
(0,337)\end{array}$ & $\begin{array}{c}0,888^{* * *} \\
(0,020)\end{array}$ & $\begin{array}{c}0,734^{* * *} \\
(0,123)\end{array}$ & $\begin{array}{c}0,859^{* * *} \\
(0,039)\end{array}$ & $\begin{array}{c}0,714^{* * *} \\
(0,073)\end{array}$ & $\begin{array}{c}0,950^{* * *} \\
(0,024)\end{array}$ & $\begin{array}{c}0,965^{* * *} \\
(0,034)\end{array}$ \\
\hline$f_{E X T}$ & $\begin{array}{c}0,004^{* * *} \\
(0,001)\end{array}$ & $\begin{array}{l}-0,001 \\
(0,005)\end{array}$ & $\begin{array}{l}0,006^{* *} \\
(0,002)\end{array}$ & $\begin{array}{c}0,008 \\
(0,006)\end{array}$ & $\begin{array}{l}0,005^{* * *} \\
(0,001)\end{array}$ & $\begin{array}{l}0,007^{* *} \\
(0,003)\end{array}$ & $\begin{array}{l}0,002^{* * *} \\
(0,001)\end{array}$ & $\begin{array}{l}-0,0002 \\
(0,0004)\end{array}$ \\
\hline$\tilde{\pi}$ & $\begin{array}{c}-0,033^{* *} \\
(0,013)\end{array}$ & $\begin{array}{c}-1,024^{* *} \\
(0,439)\end{array}$ & $\begin{array}{l}-0,007 \\
(0,034)\end{array}$ & $\begin{array}{c}0,048 \\
(0,163) \\
\end{array}$ & $\begin{array}{l}-0,032 \\
(0,031)\end{array}$ & $\begin{array}{l}-0,040 \\
(0,048)\end{array}$ & $\begin{array}{c}-0,027^{* * *} \\
(0,010)\end{array}$ & $\begin{array}{c}-0,053^{* * *} \\
(0,010)\end{array}$ \\
\hline$\widetilde{r}$ & $\begin{array}{c}0,0004^{* * *} \\
(0,0001)\end{array}$ & $\begin{array}{c}0,001 \\
(0,001)\end{array}$ & $\begin{array}{c}-0,001^{* * *} \\
(0,0002)\end{array}$ & $\begin{array}{c}-0,003^{* * *} \\
(0,001)\end{array}$ & $\begin{array}{c}-0,0002 \\
(0,0002)\end{array}$ & $\begin{array}{l}-0,001^{*} \\
(0,0003)\end{array}$ & $\begin{array}{c}-0,0003^{\text {*** }} \\
(0,0001)\end{array}$ & $\begin{array}{c}-0,0003^{* * *} \\
(0,00005)\end{array}$ \\
\hline$\widetilde{s}$ & $\begin{array}{c}-0,001^{* * *} \\
(0,0005)\end{array}$ & $\begin{array}{l}-0,000 \\
(0,001)\end{array}$ & $\begin{array}{l}0,00001 \\
(0,0002)\end{array}$ & $\begin{array}{l}0,002^{* * *} \\
(0,001)\end{array}$ & $\begin{array}{c}-0,0004^{*} \\
(0,0002)\end{array}$ & $\begin{array}{l}-0,0001 \\
(0,0003)\end{array}$ & $\begin{array}{l}0,0001^{*} \\
(0,0001)\end{array}$ & $\begin{array}{c}0,00004 \\
(0,00005)\end{array}$ \\
\hline$\widetilde{q}$ & $\begin{array}{l}0,0003 \\
(0,007)\end{array}$ & $\begin{array}{c}0,032 \\
(0,042)\end{array}$ & $\begin{array}{c}0,095^{* * *} \\
(0,020)\end{array}$ & $\begin{array}{c}0,523^{* * *} \\
(0,118)\end{array}$ & $\begin{array}{c}0,048^{* * *} \\
(0,017)\end{array}$ & $\begin{array}{c}0,212^{* * *} \\
(0,048)\end{array}$ & $\begin{array}{c}0,013^{* * *} \\
(0,005)\end{array}$ & $\begin{array}{c}0,011 \\
(0,008)\end{array}$ \\
\hline$\widetilde{g}$ & $\begin{array}{l}-0,046 \\
(0,046)\end{array}$ & $\begin{array}{c}-5,436^{* *} \\
(2,102)\end{array}$ & $\begin{array}{c}0,091 \\
(0,101) \\
\end{array}$ & $\begin{array}{c}-0,419^{*} \\
(0,241)\end{array}$ & $\begin{array}{c}0,105 \\
(0,096)\end{array}$ & $\begin{array}{l}-0,202^{*} \\
(0,104)\end{array}$ & $\begin{array}{c}0,001 \\
(0,035)\end{array}$ & $\begin{array}{c}0,063 \\
(0,039)\end{array}$ \\
\hline DFLEX & $\begin{array}{c}-0,002^{* * *} \\
(0,001)\end{array}$ & $\begin{array}{c}-0,021^{* *} \\
(0,010) \\
\end{array}$ & $\begin{array}{l}0,0003 \\
(0,002) \\
\end{array}$ & $\begin{array}{c}0,006 \\
(0,011) \\
\end{array}$ & $\begin{array}{l}- \\
-\end{array}$ & $\begin{array}{l}- \\
- \\
\end{array}$ & $\begin{array}{c}-0,0008 \\
(0,001)\end{array}$ & $\begin{array}{c}-0,001 \\
(0,0005)\end{array}$ \\
\hline$\widetilde{a}$ & $\begin{array}{c}0,780^{* * *} \\
(0,189)\end{array}$ & $\begin{array}{l}-1,894 \\
(1,613)\end{array}$ & $\begin{array}{l}-0,593 \\
(0,415)\end{array}$ & $\begin{array}{c}-2,744^{* *} \\
(1,123)\end{array}$ & $\begin{array}{c}0,062 \\
(0,277)\end{array}$ & $\begin{array}{l}0,974^{* *} \\
(0,418)\end{array}$ & $\begin{array}{l}-0,072 \\
(0,097)\end{array}$ & $\begin{array}{c}0,081 \\
(0,133)\end{array}$ \\
\hline Constante & $\begin{array}{c}0,002^{* * *} \\
(0,001)\end{array}$ & $\begin{array}{c}0,008 \\
(0,006) \\
\end{array}$ & $\begin{array}{l}0,0002 \\
(0,002) \\
\end{array}$ & $\begin{array}{l}-0,001 \\
(0,011)\end{array}$ & $\begin{array}{c}0,0005^{*} \\
(0,0003)\end{array}$ & $\begin{array}{c}0,00002 \\
(0,001) \\
\end{array}$ & $\begin{array}{c}0,001 \\
(0,001)\end{array}$ & $\begin{array}{l}0,001^{* * *} \\
(0,0004)\end{array}$ \\
\hline No. Obs. & 280 & 280 & 280 & 280 & 197 & 197 & 280 & 280 \\
\hline $\mathrm{R}^{2}$ & 0,989 & $-1,558$ & 0,982 & 0,749 & 0,988 & 0,898 & 0,977 & 0,963 \\
\hline
\end{tabular}

Notas: erros robustos em parêntesis, ${ }^{* * *} \mathrm{p}<0,01,{ }^{* *} \mathrm{p}<0,05 \mathrm{e}^{*} \mathrm{p}<0,1$. 
das novas estimações que assumiram a exogeneidade de $f_{E X T}$ indicam que a vulnerabilidade externa se manteve pró-cíclica, um resultado estatisticamente significante em seis das oito regressões estimadas.

\section{Conclusão}

Este trabalho analisou a importância da vulnerabilidade externa para os ciclos econômicos no Brasil. O trabalho inovou ao utilizar o modelo de fator dinâmico para derivar um indicador de vulnerabilidade externa, uma ferramenta ainda não utilizada em análises semelhantes já realizadas para a economia brasileira. A relação entre esse indicador e o comportamento cíclico da produção foi fundamentada teoricamente em modelos DSGE Novo-Keynesianos e testada empiricamente com o uso do método generalizado dos momentos.

Os resultados indicaram que uma maior vulnerabilidade externa estimula a atividade econômica no curto prazo. O crescente endividamento externo e a apreciação cambial, que são observados durante a expansão da atividade econômica, levam à maior vulnerabilidade externa e podem desencadear uma recessão no futuro. Não obstante, esses resultados precisam ser considerados com cautela, pois são sensíveis ao filtro utilizado para derivar os componentes cíclicos das variáveis. Ademais, sua representatividade econômica também é limitada.

A análise empírica também mostrou que as taxas reais de juros e os choques de produtividade são importantes para os ciclos econômicos no Brasil. Elevações nas taxas reais de juros levam a contrações na atividade econômica, um resultado que é robusto à especificação do modelo econométrico estimado e que é previsto pelo modelo teórico e por estudos empíricos anteriores (Kanczuk 2004). Já os choques de produtividade contribuem para a expansão na produção, mas levam à contração no emprego em algumas das especificações do modelo, um resultado também previsto por modelos teóricos que pressupõem concorrência imperfeita (Gali 1999). Quanto às demais variáveis de controle, não apresentaram um desempenho consistente.

É importante, portanto, que as autoridades econômicas ponderem os benefícios associados à uma crescente fragilidade externa para a promoção do emprego e renda com os custos relacionados à maior suscetibilidade do país a choques externos e crises financeiras.

\section{Referências Bibliográficas}

Aghion, P., Bacchetta, P., Ranciere, R. \& Rogoff, K. (2009). Exchange rate volatility and productivity growth: The role of financial development. Journal of Monetary Economics, Amsterdam,v. 56, n. 4, p. 494-513.

Ahrend, R. \& Goujard, A. (2014). Drivers of systemic banking crises: The role of financial account structure and financial integration. International Finance, New Jersey, v. 17, n. 2, p. 135-160.

Alesina, A. \& Tabellini, G. (2005). Why is fiscal policy often procyclical?. NBER Working Paper, Cambridge, n. 11, p. 600.

Ascari, G., Magnusson, L. M. \& Mavroeidis, S. (2019). Empirical evidence on the Euler equation for consumption in the US. Journal of Monetary Economics, Amsterdam, v. 4, n. 4. 
Tabela 4: Vulnerabilidade Externa como Variável Exógena: Filtro CF

\begin{tabular}{|c|c|c|c|c|c|c|c|c|}
\hline \multicolumn{9}{|c|}{ Taxa de Câmbio e Endividamento Externo: Comportamento Pró-cíclico } \\
\hline & GMM2S & $\begin{array}{l}\text { GMM- } \\
\text { CUE }\end{array}$ & GMM2S & $\begin{array}{c}\text { GMM- } \\
\text { CUE }\end{array}$ & GMM2S & $\begin{array}{c}\text { GMM- } \\
\text { CUE }\end{array}$ & GMM2S & $\begin{array}{l}\text { GMM- } \\
\text { CUE }\end{array}$ \\
\hline & $\widetilde{y}=\widetilde{y}_{P I B}$ & $\widetilde{y}=\widetilde{y_{P I B}}$ & $\widetilde{y}=\widetilde{y}_{I N D}$ & $\widetilde{y}=\widetilde{y}_{I N D}$ & $\widetilde{y}=\widetilde{y}_{I B C}$ & $\widetilde{y}=\widetilde{y}_{I B C}$ & $\widetilde{y}=\widetilde{y_{E M P}}$ & $\widetilde{y}=\widetilde{y}_{E M P}$ \\
\hline$\widetilde{\varepsilon}$ & $\begin{array}{c}-0,007^{* * *} \\
(0,001)\end{array}$ & $\begin{array}{c}-0,005^{* * *} \\
(0,001)\end{array}$ & $\begin{array}{c}-0,009^{* * *} \\
(0,002)\end{array}$ & $\begin{array}{c}-0,012^{* * *} \\
(0,003)\end{array}$ & $\begin{array}{c}-0,003^{* * *} \\
(0,001)\end{array}$ & $\begin{array}{c}0,001 \\
(0,002)\end{array}$ & $\begin{array}{l}-0,001 \\
(0,001)\end{array}$ & $\begin{array}{l}0,003^{* *} \\
(0,001)\end{array}$ \\
\hline$\widetilde{B^{*}}$ & $\begin{array}{c}-0,060^{* * *} \\
(0,020)\end{array}$ & $\begin{array}{l}-0,043 \\
(0,027)\end{array}$ & $\begin{array}{c}0,238^{* * *} \\
(0,068)\end{array}$ & $\begin{array}{l}-0,039 \\
(0,045)\end{array}$ & $\begin{array}{c}0,128^{* * *} \\
(0,023)\end{array}$ & $\begin{array}{c}0,110^{* * *} \\
(0,026)\end{array}$ & $\begin{array}{c}0,010 \\
(0,017)\end{array}$ & $\begin{array}{l}0,049^{* *} \\
(0,024)\end{array}$ \\
\hline \multicolumn{9}{|c|}{ Vulnerabilidade Externa: Variável Exógena } \\
\hline & GMM2S & $\begin{array}{l}\text { GMM- } \\
\text { CUE }\end{array}$ & GMM2S & $\begin{array}{c}\text { GMM- } \\
\text { CUE }\end{array}$ & GMM2S & $\begin{array}{l}\text { GMM- } \\
\text { CUE }\end{array}$ & GMM2S & $\begin{array}{l}\text { GMM- } \\
\text { CUE }\end{array}$ \\
\hline & $\widetilde{y}=\widetilde{y_{P} I B}$ & $\widetilde{y}=\widetilde{y}_{P I B}$ & $\widetilde{y}=\widetilde{y}_{I N D}$ & $\widetilde{y}=\widetilde{y}_{I N D}$ & $\widetilde{y}=\widetilde{y}_{I B C}$ & $\widetilde{y}=\widetilde{y}_{I B C}$ & $\widetilde{y}=\widetilde{y}_{E M P}$ & $\widetilde{y}=\widetilde{y}_{E M P}$ \\
\hline$f_{E X T}$ & $\begin{array}{l}0,001^{* *} \\
(0,001)\end{array}$ & $\begin{array}{c}0,002 \\
(0,003)\end{array}$ & $\begin{array}{l}0,002^{* *} \\
(0,001)\end{array}$ & $\begin{array}{c}0,003 \\
(0,005)\end{array}$ & $\begin{array}{l}0,002^{* *} \\
(0,001)\end{array}$ & $\begin{array}{l}0,008^{* * * *} \\
(0,002)\end{array}$ & $\begin{array}{l}0,001^{* *} \\
(0,000)\end{array}$ & $\begin{array}{l}0,001^{* * * *} \\
(0,000)\end{array}$ \\
\hline Teste C & 0,739 & 0,832 & 0,988 & 0,964 & 0,660 & 0,482 & 0,969 & 0,969 \\
\hline
\end{tabular}

Fonte: elaboração própria.

Notas: erros robustos em parêntesis, ${ }^{* * *} \mathrm{p}<0,01,{ }^{* *} \mathrm{p}<0,05 \mathrm{e}^{*} \mathrm{p}<0,1 ; \widetilde{\varepsilon}$ e $\widetilde{B^{*}}$ representam os componentes cíclicos da

taxa de câmbio e do endividamento externo em razão do PIB; resultados completos dessas estimativas podem ser obtidos mediante solicitação aos autores. 
Backus, D., Kehoe, P. \& Kydland, F. (1992). International real business cycles. Journal of Political Economy, Chicago, v. 100, p. 745-775.

Barros, D. C. (2008). Fragilidade financeira externa no Brasil: evolução recente e impactos sobre a taxa de juros. Belo Horizonte: CEDEPLAR/UFMG.

Baum, C. F., Schaffer, M. E. \& Stillman, S. (2007). Enhanced routines for instrumental variables/generalized method of moments estimation and testing. The Stata Journal, v. 7, n. 4, p. 465-506.

Baxter, M. \& King, R. G. (1999). Measuring business cycles: approximate band-pass filters for economic time series. Review of economics and statistics, Cambridge, v. 81 , n. 4 , p. 575-593.

BCB - Banco Central do Brasil (2016). Séries Temporais. Disponível em: http://www.bcb.gov.br. Acesso em: 07 mai. 2020.

Bernanke, B., Gertler, M. \& Gilchrist, S. (1998). The financial accelerator in a quantitative business cycle framework. National Bureau of Economic Research Working Paper, Cambridge, n. 6455.

Bonciani, D. \& Ricci, M. (2020). The international effects of global financial uncertainty shocks. Journal of International Money and Finance, Amsterdam, v. 109 , p. 1-21.

Calvo, G. \& Talvi, E. (2008). Sudden Stop, Financial Factors and Economic Collapse: A View from the Latin American Frontlines. In: SERRA, N.; STIGLITZ, J. E. (orgs.) The Washington Consensus Reconsidered: Towards a New Global Governance. New York: Oxford University Press.

CBOE - Chicago Board of Exchange (2016). Cboe Volatility Index. Chicago: Cboe. Disponível em: http://www.cboe.com/index/dashboard/vix\#vixperformance. Acesso em: 05 nov. 2020.

Chaussé, P. (2010). Computing generalized method of moments and generalized empirical likelihood with R. Journal of Statistical Software, Austria, v. 34, n. 11, p. 1-35.

Christiano, L. \& Eichenbaum, M. (1992). Current real-business-cycle theories and aggregate labor-market fluctuations. The American Economic Review, Nashville, p. 430-450.

Christiano, L., Eichenbaum, M. \& Evans, C. (2005). Nominal rigidities and the dynamic effects of a shock to monetary policy. Journal of political Economy, Chicago, v. 113, n. 1, p. 1-45.

Christiano, L. \& Fitzgerald, T. (2003). The band-pass filter. International Economic Review, New Jersey, v. 44, n. 2, p. 435-465.

Clarida, R., Gali, J. \& Gertler, M. (1999). The science of monetary policy: a new Keynesian perspective. Journal of economic literature, Nashville, v. 37, n. 4, p. 1661-1707. 
CODACE - Comitê de Datação dos Ciclos Econômicos (2016). Comitê de Datação dos Ciclos Econômicos. Rio de Janeiro: FGV/IBRE. Disponível em: https://portalibre.fgv.br/sites/default/files/2020-06/comunicadodo-comite-de-datacao-de-ciclos-economicos-29_06_2020-1.pdf. Acesso em: 22 jul. 2020.

Correa, V., Munhoz, V. \& Pereira, V. (2012). A volatilidade da conta financeira do balanço de pagamentos de países selecionados da América Latina e da Ásia no período 1990-2010. In: Anais do Encontro Internacional da Associação Keynesiana Brasileira, v. 5.

Correia, I., Neves, J. C. \& Rebelo, S. (1995). Business cycles in a small open economy. European Economic Review, Amsterdam, v. 39, n. 6, p. 1089-1113.

Cravino, J. \& Levchenko, A. A. (2016). Multinational firms and international business cycle transmission. The Quarterly Journal of Economics, Cambridge, v. 132 , n. 2, p. $921-962$.

Dabla-Norris, E. \& Gündüz, Y. B. (2014). Exogenous shocks and growth crises in low-income countries: A vulnerability index. World Development, Amsterdam, v. 59, p. 360-378.

De Paula, L. F. R. \& Alves JR, A. J. (2000). External financial fragility and the 1998-1999 Brazilian currency crisis. Journal of Post Keynesian Economics, Abingdon, v. 22, n. 4, p. 589-617.

De Paula, L. F. R., Pires, M. C. C., Faria Junior, J. A. \& Meyer, T. R. (2012). Liberalização financeira, performance econômica e estabilidade macroeconômica no Brasil: uma análise do período 1994-2007. Revista Nova Economia, Belo Horizonte, v. 22, n. 3, p. 561-596.

Demirguc-Kunt, A., Horvath, B. L. \& Huizinga, H. (2017). Foreign Banks and International Transmission of Monetary Policy: Evidence from the Syndicated Loan Market. World Bank Policy Research Working Paper, Washington, n. 7937.

Dennis, R. (2009). Consumption habits in a new Keynesian business cycle model. Journal of Money, Credit and Banking, Columbus, v. 41, n. 5, p. 10151030 .

Di Giovanni, J., Levchenko, A. A. \& Mejean, I. (2018). The micro origins of international business-cycle comovement. American Economic Review, Nashville, v. 108, n. 1, p. 82-108.

Easterly, W. R. \& Kraay, A. (2000). Small states. Small problem? Income, growth, and volatility in small states. World Development, Amsterdam, v. 28, n. 11, p. 2013-2027.

Elekdag, S., Justiniano, A. \& Tchakarov, I. (2006). An estimated small open economy model of the financial accelerator. IMF Staff Papers, Washington, v. 53, n. 2, p. 219-241.

Fernández, A., Schmitt-Grohé, S. \& Uribe, M. (2017). World shocks, world prices, and business cycles: An empirical investigation. Journal of International Economics, Amsterdam, v. 108, n. S1, p. 2-14. 
Frankel, J. \& Saravelos, G. (2012). Can leading indicators assess country vulnerability? Evidence from the 2008-09 global financial crisis. Journal of International Economics, Amsterdam, v. 87, n. 2, p. 216-231.

FRB - Federal Reserve Bank of ST (2020). Federal Reserve Economic Database. Louis. Disponível em: https://fred.stlouisfed.org/. Acesso em: 15 mai. 2020.

Fuhrer, J. C. \& Rudebusch, G. D. (2004). Estimating the Euler equation for output. Journal of Monetary Economics, Amsterdam, v. 51, n. 6, p. 1133-1153.

Fève, P., Matheron, J. \& Sahuc, J. G. (2013). A pitfall with estimated DSGEbased government spending multipliers. American Economic Journal: Macroeconomics, Nashville, v. 5, n. 4, p. 141-78.

Gali, J. (1999). Technology, employment, and the business cycle: do technology shocks explain aggregate fluctuations?. American Economic Review, Nashville, v. 89 , n. 1, p. $249-271$.

Gali, J. \& Gertler, M. (1999). Inflation dynamics: A structural econometric analysis. Journal of Monetary Economics, Amsterdam, v. 44, n. 2, p. 195-222.

Gali, J. \& Monacelli, T. (2005). Monetary policy and exchange rate volatility in a small open economy. The Review of Economic Studies, Oxford, v. 72, n. 3, p. 707-734.

Geweke, J. (1977). The dynamic factor analysis of economic time series models. In: AIGNER, D. J.; GOLDBERGER, A. S. (orgs.) Latent Variables in Socioeconomic Models Amsterdam: North-Holland. p. 365-383.

Gilchrist, S., Ortiz, A. \& Zakrajsek, E. (2009). Credit risk and the macroeconomy: Evidence from an estimated dsge model. Unpublished manuscript, Boston, v. 13.

Glick, R. \& Rose, A. (1999). Contagion and trade: Why are currency crises regional. Journal of International Money and Finance, Amsterdam, v. 18, n. 4, p. 630-636.

Goldfajn, I. \& Minella, A. (2005). Capital flows and controls in Brazil: what have we learned?. National Bureau of Economic Research Working Paper, Cambridge, n. 11640.

Gourinchas, P. O. \& Obstfeld, M. (2012). Stories of the twentieth century for the twenty-first. American Economic Journal: Macroeconomics, Nashville, v. 4, n. 1, p. 226-65.

Haas, R. \& Lelyveld, I. (2014). Multinational banks and the global financial crisis: Weathering the perfect storm?. Journal of Money, Credit and Banking, Columbus, v. 46, p. 333-364.

Hamilton, J. D. (2018). Why you should never use the Hodrick-Prescott filter. Review of Economics and Statistics, Cambridge, v. 100, n. 5, p. 831-843.

Hansen, L., Heaton, J. \& Yaron, A. (1996). Finite-sample properties of some alternative GMM estimators. Journal of Business E Economic Statistics, Abingdon, v. 14, n. 3 , p. $262-280$. 
Hansen, L. \& Singleton, K. J. (1982). Generalized instrumental variables estimation of nonlinear rational expectations models. Econometrica, New Haven, p. $1269-1286$.

Hodrick, R. J. \& Prescott, E. C. (1997). Postwar US business cycles: an empirical investigation. Journal of Money, Credit, and Banking, Columbus, p. 1-16.

IMF - International Moneraty Fund (2000). Debt- and Reserve-Related Indicators of External Vulnerability. IMF Policy Papers.

IPEA - Instituto de Pesquisa Econômica Aplicada (2020). IPEA Data. Disponível em: http://www.ipeadata.gov.br. Acesso em: 06 mai. 2020.

Kaltenbrunner, A. \& Painceira, J. P. (2014). Developing countries' changing nature of financial integration and new forms of external vulnerability: the Brazilian experience. Cambridge Journal of Economics, Oxford, v. 39, n. 5, p. 1281-1306.

Kaminsky, G. L., Reinhart, C. M. \& Vegh, C. A. (2004). When It Rains, It Pours: Procyclical Capital Flows and Macroeconomic Policies. NBER Macroeconomics Annual, Cambridge, v. 19, p. 11-53.

Kaminsky, G., Lizondo, S. \& Reinhart, C. M. (1998). Leading indicators of currency crises. IMF Staff Papers, Washington, v. 45, n. 1, p. 1-48.

Kanczuk, F. (2004). Real interest rates and Brazilian business cycles. Review of Economic Dynamics, Amsterdam, v. 7, n. 2, p. 436-455.

Karras, G. \& Song, F. (1996). Sources of business-cycle volatility: an exploratory study on a sample of OECD countries. Journal of Macroeconomics, Amsterdam, v. 18 , p. 621-637.

Krugman, P. (1999). What Happened to Asia. In: Sato R.; Ramachandran R.V.; Mino K. (orgs.) Global Competition and Integration. Research Monographs in Japan-U.S. Business \& Economics. Boston: Springer. v. 4.

Kydland, F. E. \& Prescott, E. C. (1982). Time to build and aggregate fluctuations. Econometrica, New Haven, v. 50, n. 6, p. 1345-1370.

Leeper, E. M., Plante, M. \& Traum, N. (2010). Dynamics of fiscal financing in the United States. Journal of Econometrics, Purmerend, v. 156, n. 2, p. 304321.

Loayza, N. V. \& Raddatz, C. (2007). The structural determinants of external vulnerability. The World Bank Economic Review, Washington, v. 21, n. 3, p. 359-387.

Long, J. B. \& Plosser, C. I. (1983). Real business cycles. Journal of political Economy, Chicago, v. 91, n. 1, p. 39-69.

Mendoza, E. G. (1991). Real business cycles in a small open economy. American Economic Review, Nashville, p. 797-818.

Mendoza, E. G. (1995). The terms of trade, the real exchange rate, and economic fluctuations. International Economic Review, New Jersey, p. 101-137. 
Minsky, H. P. (1986). Stabilizing an Unstable Economy. London: Yale University Press.

Montalbano, P. (2011). Trade openness and developing countries' vulnerability: Concepts, misconceptions, and directions for research. World Development, Amsterdam, v. 39, n. 9, p. 1489-1502.

Moslares, C. \& Ekanayake, E. M. (2018). The Effect of Real Exchange Rate Volatility On Exports In The Baltic Region. The International Journal of Business and Finance Research, Hilo, v. 12, n. 1, p. 23-38.

Moura, B., Tiryaki, G. F. \& Teixeira, D. N. (2020). Fragilidade fiscal e os ciclos econômicos no Brasil pós-Plano Real: evidências de um modelo de fator dinâmico associado à análise VAR. Revista Nova Conjuntura, Rio de Janeiro, v. 30, n. 2, p. 517-549.

Ocampo, J. A. (2011). Balance of payments dominance: Its implications for macroeconomic policy. São Paulo: FGV, manuscrito.

Oreiro, J. L., Basilio, F. A. C. \& Souza, G. J. G. (2014). Effects of overvaluation and exchange rate volatility over industrial investment: empirical evidence and economic policy proposals for Brazil. Brazilian Journal of Political Economy, São Paulo, v. 34, n. 3, p. 347-369.

Ravn, M. O. \& Uhlig, H. (2002). On adjusting the Hodrick-Prescott filter for the frequency of observations. Review of economics and statistics, Cambridge, v. 84, n. 2 , p. $371-376$.

Ravn, M., Schmitt-Grohé, S. \& Uribe, M. (2006). Deep habits. Review of Economic Studies, Oxford, v. 73, n. 1, p. 195-218.

Reyes-Heroles, R. \& Tenorio, G. (2017). Interest Rate Volatility and Sudden Stops: An Empirical Investigation. Board of Governors of the Federal Reserve System - International Finance Discussion Papers, Washington, n. 1209.

Ribeiro, F. J. (2016). Reavaliando a vulnerabilidade externa da economia brasileira, IPEA Texto para Discussão, n. 2247.

Rohn, O., Sanchez, A. C., Hermansen, M. \& Rasmussen, M. (2015). Economic resilience: A new set of vulnerability indicators for OECD countries. OECD Economics Department Working Papers, Paris, n. 1249.

Salles, A. O. T., Rodrigues, A. F. \& Terra, F. H. B. (2018). Fragilidade Financeira Externa da Economia Brasileira: uma Interpretação Minskyana do Período 1994/2014. Revista de Desenvolvimento Econômico, Salvador, v. 3, n. 38.

Sarto, V. H. R. \& Almeida, L. T. (2015). Currency crisis and external fragility: a Minskyan interpretation applied to the Brazilian economy between 1999 and 2013. Nova Economia, Belo Horizonte, v. 25, n. especial, p. 891-938.

Scheubel, B., Stracca, L. \& Tille, C. (2019). The global financial cycle and capital flow episodes: a wobbly link?. CESifo Working Paper, Munich, n. 7967.

Shin, H. S. (2016). Global liquidity and procyclicality. In: Presentation at the World Bank Conference. The State of Economics, the State of the World. 
Siklos, P. L. (2018). Boom-and-bust cycles in emerging markets: How important is the exchange rate?. Journal of Macroeconomics, Amsterdam, v. 56, p. 172-187.

Smets, F. \& Wouters, R. (2007). Shocks and frictions in US business cycles: A Bayesian DSGE approach. American economic review, Nashville, v. 97, n. 3, p. 586-606.

Staiger, D. \& Stock, J. H. (1997). Instrumental Variables Regression with Weak Instruments. Econometrica, New Haven, v. 65, n. 3, p. 557-586.

Stock, J. H. \& Watson, M. (2011). Dynamic factor models. Oxford Handbook on Economic Forecasting.

Teixeira, D. N., Tiryaki, G. F. \& Drummond, C. E. I. (2020). Fragilidade Financeira e Volatilidade dos Ciclos Econômicos no Brasil Pós-Plano Real. Estudos Econômicos, São Paulo, v. 50, n. 1, p. 125-158.

Tenreyro, S. (2007). On the trade impact of nominal exchange rate volatility. Journal of Development Economics, Amsterdam, v. 82, n. 2, p. 485-508.

Uhlig, H. (2010). Some fiscal calculus. American Economic Review, Nashville, v. 100 , n. 2 , p. $30-34$.

Van Der Laan, C. R., Cunha, A. M. \& Lélis, M. T. C. (2011). Liberalização financeira externa: investigando alguns efeitos macroeconômicos no Brasil entre 1994 e 2006. Economia e Sociedade, Campinas, v. 20, n. 1, p. 79-112.

\section{Apêndice A}


Tabela A.1: Vulnerabilidade Externa: Testes de Raiz Unitária

\begin{tabular}{|c|c|c|c|c|c|c|}
\hline & \multirow{2}{*}{\multicolumn{2}{|c|}{$\begin{array}{c}\text { ADF } \\
\text { H0: } \\
\text { não } \\
\text { estacionariedade }\end{array}$}} & \multirow{2}{*}{\multicolumn{2}{|c|}{$\begin{array}{c}\text { ADF-GLS } \\
\text { H0: } \\
\text { não } \\
\text { estacionariedade } \\
\end{array}$}} & \multicolumn{2}{|c|}{ KPSS } \\
\hline & & & & & \multicolumn{2}{|c|}{$\begin{array}{c}\text { H0: } \\
\text { estacionariedade }\end{array}$} \\
\hline & Nível & 1as Dif, & Nível & 1as Dif, & Nível & 1as Dif, \\
\hline \multicolumn{7}{|l|}{ VARIÁVEL: ABERTURA } \\
\hline Constante & $-2,357$ & $-4,061^{* * *}$ & 0,224 & $-2,842^{* * *}$ & $0,872^{* * *}$ & 0,171 \\
\hline Constante e Tendência & $-2,249$ & $-4,149^{* * *}$ & $-1,322$ & $-3,455^{* *}$ & $0,309^{* * *}$ & 0,116 \\
\hline \multicolumn{7}{|c|}{ VARIÁVEL: EMPTOTEXP } \\
\hline \begin{tabular}{l|} 
Constante \\
\end{tabular} & $-2,439$ & $-8,444^{* * *}$ & $1,665^{*}$ & $-7,930^{* * *}$ & 0,142 & - \\
\hline Constante e Tendência & $-2,470$ & $-8,429^{* * *}$ & $-2,107$ & $-8,089^{* * *}$ & 0,114 & - \\
\hline \multicolumn{7}{|c|}{ VARIÁVEL: EMPTOTPIB } \\
\hline \begin{tabular}{l|l} 
Constante &
\end{tabular} & $-2,366$ & $-7,915^{* * *}$ & $-2,054^{* *}$ & - & 0,175 & - \\
\hline Constante e Tendência & $-2,427$ & $-7,901^{* * *}$ & $-2,220$ & $-7,570^{* * *}$ & 0,106 & - \\
\hline \multicolumn{7}{|c|}{ VARIÁVEL: INVCARTPIB } \\
\hline \begin{tabular}{l|} 
Constante \\
\end{tabular} & $-2,337$ & $-5,606^{* * *}$ & $-1,915^{*}$ & $-2,744^{* * *}$ & 0,274 & - \\
\hline Constante e Tendência & $-2,455$ & $-5,598^{* * *}$ & $-2,419$ & $-4,316^{* * *}$ & 0,184 & - \\
\hline \multicolumn{7}{|l|}{ VARIÁVEL: INVDIRPIB } \\
\hline Constante & $-2,006$ & $-15,366^{* * *}$ & 0,559 & $-15,321^{* *}$ & 0,218 & - \\
\hline Constante e Tendência & $-1,907$ & $-15,364^{* * *}$ & $-1,303$ & $-15,297^{* * *}$ & $\mid 0,179^{* *}$ & 0,090 \\
\hline \multicolumn{7}{|c|}{ VARIÁVEL: LIBOR12M } \\
\hline Constante & $-1,353$ & $-11,584^{* * *}$ & $-0,571$ & $-3,931^{* * *}$ & $1,169^{* * *}$ & 0,082 \\
\hline Constante e Tendência & $-1,590$ & $-11,571^{* * *}$ & $-1,637$ & $-10,630^{* * *}$ & * $0,139^{*}$ & 0,067 \\
\hline \multicolumn{7}{|c|}{ VARIÁVEL: LIBOR3M } \\
\hline \begin{tabular}{l|l} 
Constante & \\
\end{tabular} & $-1,601$ & $-8,376^{* * *}$ & 0,621 & $-3,042^{* * *}$ & $1,152^{* * *}$ & 0,104 \\
\hline Constante e Tendência & $-1,599$ & $-8,394^{* * *}$ & $-1,656$ & $-7,059^{* * *}$ & $0,139^{*}$ & 0,061 \\
\hline \multicolumn{7}{|l|}{ VARIÁVEL: LNEMBI } \\
\hline $\begin{array}{ll}\text { Constante } \\
\end{array}$ & $-1,957$ & $-13,719^{* * *}$ & 1,012 & $-6,139^{* * *}$ & $1,224^{* * *}$ & 0,048 \\
\hline Constante e Tendência & $-2,600$ & $-13,695^{* * *}$ & $-2,610^{*}$ & $-12,768^{* * *}$ & $0,218^{* * *}$ & 0,042 \\
\hline \multicolumn{7}{|l|}{ VARIÁVEL: RESIMP } \\
\hline $\begin{array}{l}\text { Constante } \\
\text { nate }\end{array}$ & $-0,919$ & $13,228^{* * *}$ & $-0,707$ & $-3,181^{* * *}$ & $1,592^{* * *}$ & 0,090 \\
\hline Constante e Tendência & $-3,777^{* *}$ & - & $-2,416$ & $-4,458^{* * *}$ & $0,211^{* * *}$ & 0,066 \\
\hline \multicolumn{7}{|l|}{ VARIÁVEL: RESM2 } \\
\hline Constante & $-2,886^{* *}$ & - & $-0,280$ & $-1,362$ & 0,235 & $\overline{-}$ \\
\hline Constante e Tendência & $-2,757$ & $-7,530^{* * *}$ & $-1,376$ & $-2,604$ & $0,221^{* * *}$ & 0,130 \\
\hline \multicolumn{7}{|l|}{ VARIÁVEL: RESPIB } \\
\hline Constante & $-0,316$ & $-13,888^{* * *}$ & 0,639 & $-4,938^{* * *}$ & $1,874^{* * *}$ & 0,086 \\
\hline Constante e Tendência & $-2,831$ & $-13,891^{* * *}$ & $-1,745$ & $-8,852^{* * *}$ & $0,251^{* * *}$ & 0,046 \\
\hline \multicolumn{7}{|c|}{ VARIÁVEL: TXROLTOT } \\
\hline \begin{tabular}{l|} 
Constante \\
\end{tabular} & $-2,962^{* *}$ & - & \begin{tabular}{|l|l|}
$-1,558$ \\
-1
\end{tabular} & $-2,308^{* *}$ & 0,198 & - \\
\hline Constante e Tendência & $-2,949$ & $-12,146^{* * *}$ & $-2,539$ & $-9,823^{* * *}$ & $0,156^{* *}$ & 0,049 \\
\hline \multicolumn{7}{|c|}{ VARIÁVEL: VOLCAMBREAL } \\
\hline Constante & $-3,586^{* * *}$ & - & $-2,882^{* * *}$ & - & 0,077 & - \\
\hline Constante e Tendência & $-3,571^{* *}$ & - & $-3,348^{* *}$ & - & 0,080 & - \\
\hline
\end{tabular}


Apêndice B 
Tabela B.1: Estatísticas Descritivas e Correlações Cruzadas

\begin{tabular}{|c|c|c|c|c|c|c|c|c|c|c|c|c|c|c|c|c|c|}
\hline \multicolumn{7}{|c|}{ Estatísticas Descritivas } & \multicolumn{11}{|c|}{ Correlações Cruzadas } \\
\hline & Variável & Obs. & Média & Desv.Pad. & Min & Max & $\widetilde{y}_{P I B}$ & $\widetilde{y}_{I N D}$ & $\widetilde{y}_{I B C}$ & $\widetilde{y}_{E M P}$ & $\widetilde{a}$ & $f_{E X T}$ & $\widetilde{\pi}$ & $\widetilde{r}$ & $\widetilde{s}$ & $\widetilde{q}$ & $\widetilde{\boldsymbol{g}}$ \\
\hline \multirow{11}{*}{ 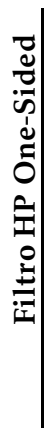 } & $\widetilde{y}_{P I B}$ & 288 & $-1,9 \mathrm{E}-11$ & 0,020 & $-0,048$ & 0,043 & 1,000 & 0,507 & 0,620 & 0,515 & 0,009 & 0,130 & $-0,737$ & $-0,095$ & $-0,456$ & 0,217 & $-0,520$ \\
\hline & $\widetilde{y}_{I N D}$ & 288 & $-6,4 \mathrm{E}-11$ & 0,037 & $-0,143$ & 0,080 & & 1,000 & 0,833 & 0,353 & 0,251 & 0,123 & $-0,419$ & $-0,193$ & $-0,431$ & 0,548 & $-0,170$ \\
\hline & $\widetilde{y}_{I B C}$ & 204 & $-7,0 \mathrm{E}-12$ & 0,021 & $-0,067$ & 0,037 & & & 1,000 & 0,529 & 0,180 & 0,075 & $-0,452$ & $-0,298$ & $-0,468$ & 0,463 & $-0,291$ \\
\hline & $\widetilde{y}_{E M P}$ & 288 & $3,3 \mathrm{E}-11$ & 0,013 & $-0,032$ & 0,034 & & & & 1,000 & $-0,046$ & 0,080 & $-0,155$ & $-0,252$ & $-0,313$ & $-0,082$ & $-0,471$ \\
\hline & $\widetilde{a}$ & 288 & $-6,8 \mathrm{E}-12$ & 0,004 & $-0,014$ & 0,017 & & & & & 1,000 & 0,207 & 0,072 & $-0,016$ & 0,088 & 0,100 & 0,033 \\
\hline & $f_{E X T}$ & 286 & $-3,1 E-02$ & 0,228 & $-0,812$ & 1,257 & & & & & & 1,000 & 0,032 & 0,220 & 0,073 & $-0,143$ & $-0,169$ \\
\hline & $\tilde{\pi}$ & 288 & $1,3 \mathrm{E}-11$ & 0,017 & $-0,034$ & 0,046 & & & & & & & 1,000 & 0,229 & 0,268 & $-0,444$ & 0,222 \\
\hline & $\widetilde{r}$ & 288 & 5,5E-09 & 4,123 & $-8,453$ & 22,098 & & & & & & & & 1,000 & 0,083 & $-0,108$ & 0,351 \\
\hline & $\widetilde{s}$ & 288 & $-1,1 \mathrm{E}-09$ & 4,279 & $-9,727$ & 22,448 & & & & & & & & & 1,000 & $-0,281$ & 0,398 \\
\hline & $\widetilde{q}$ & 284 & $-5,8 \mathrm{E}-12$ & 0,051 & $-0,149$ & 0,190 & & & & & & & & & & 1,000 & 0,199 \\
\hline & $\widetilde{\widetilde{g}}$ & 288 & $8,3 \mathrm{E}-12$ & 0,005 & $-0,010$ & 0,012 & & & & & & & & & & & 1,000 \\
\hline \multirow{11}{*}{$\begin{array}{c}0 \\
0 \\
0 \\
\vdots \\
\vdots \\
0\end{array}$} & $\widetilde{y}_{P I B}$ & 288 & 0,0001 & 0,016 & $-0,038$ & 0,032 & 1,000 & 0,630 & 0,750 & 0,511 & $-0,021$ & 0,139 & $-0,800$ & $-0,021$ & $-0,627$ & 0,408 & $-0,568$ \\
\hline & $\widetilde{\widetilde{y}}_{I N D}$ & 288 & 0,001 & 0,030 & $-0,099$ & 0,068 & & 1,000 & 0,956 & 0,390 & 0,348 & 0,193 & $-0,570$ & $-0,101$ & $-0,623$ & 0,809 & $-0,230$ \\
\hline & $\widetilde{y}_{I B C}$ & 204 & $-0,0004$ & 0,019 & $-0,052$ & 0,038 & & & 1,000 & 0,492 & 0,342 & 0,079 & $-0,692$ & $-0,166$ & $-0,651$ & 0,787 & $-0,290$ \\
\hline & $\widetilde{y}_{E M P}$ & 288 & 0,0002 & 0,008 & $-0,016$ & 0,018 & & & & 1,000 & 0,298 & 0,050 & $-0,283$ & $-0,281$ & 0,035 & 0,153 & $-0,436$ \\
\hline & $\widetilde{a}$ & 288 & $-0,0002$ & 0,002 & $-0,004$ & 0,004 & & & & & 1,000 & 0,099 & 0,059 & $-0,115$ & 0,224 & 0,260 & 0,286 \\
\hline & $f_{E X T}$ & 286 & $-0,031$ & 0,228 & $-0,812$ & 1,257 & & & & & & 1,000 & 0,076 & 0,318 & 0,068 & $-0,118$ & $-0,141$ \\
\hline & $\tilde{\pi}$ & 288 & 0,001 & 0,015 & $-0,028$ & 0,037 & & & & & & & 1,000 & 0,288 & 0,666 & $-0,500$ & 0,391 \\
\hline & $\widetilde{r}$ & 288 & $-0,010$ & 3,112 & $-7,720$ & 11,630 & & & & & & & & 1,000 & 0,059 & $-0,170$ & 0,204 \\
\hline & $\widetilde{s}$ & 288 & $-0,184$ & 3,699 & $-8,433$ & 10,514 & & & & & & & & & 1,000 & $-0,651$ & 0,417 \\
\hline & $\widetilde{q}$ & 284 & $-0,0001$ & 0,043 & $-0,149$ & 0,146 & & & & & & & & & & 1,000 & 0,043 \\
\hline & $\tilde{\widetilde{g}}$ & 288 & $-0,0002$ & 0,004 & $-0,009$ & 0,010 & & & & & & & & & & & 1,000 \\
\hline
\end{tabular}


Apêndice C Testes de Especificação 
Tabela C.1: Estimações Utilizando o Filtro HP ${ }^{1}$

\begin{tabular}{|c|c|c|c|c|c|c|c|c|c|c|c|c|}
\hline & \multicolumn{6}{|c|}{ TWO-SIDED } & \multicolumn{6}{|c|}{ ONE-SIDED } \\
\hline & (I) & (II) & (III) & (IV) & (V) & & (VII) & & $(\mathrm{IX})$ & $(\mathrm{X})$ & (XI) & (XII) \\
\hline & GMM2S & $\begin{array}{l}\text { GMM- } \\
\text { CUE }\end{array}$ & $2 S L S$ & $2 S L S$ & GMM2S & $\begin{array}{l}\text { GMM- } \\
\text { CUE }\end{array}$ & GMM2S & $\begin{array}{l}\text { GMM- } \\
\text { CUE }\end{array}$ & $2 S L S$ & $2 S L S$ & GMM2S & $\begin{array}{l}\text { GMM- } \\
\text { CUE }\end{array}$ \\
\hline & $\widetilde{y}=\widetilde{y}_{P I B}$ & $\widetilde{y}=\widetilde{y}_{P I B}$ & $\widetilde{y}=\widetilde{y}_{I N D}$ & $\widetilde{y}=\widetilde{y}_{I B C}$ & $\widetilde{y}=\widetilde{y}_{E M P}$ & $\widetilde{y}=\widetilde{y}_{E M P}$ & $\widetilde{y}=\widetilde{y}_{P I B}$ & $\widetilde{y}=\widetilde{y}_{P I B}$ & $\widetilde{y}=\widetilde{y}_{I N D}$ & $\widetilde{y}=\widetilde{y}_{I B C}$ & $\widetilde{y}=\widetilde{y}_{E M P}$ & $\widetilde{y}=\widetilde{y}_{E M P}$ \\
\hline $\begin{array}{l}\text { Cumby- } \\
\text { Huizinga AR(1) }\end{array}$ & 0,000 & 0,000 & 0,000 & 0,0075 & 0,000 & 0,000 & 0,000 & 0,000 & 0,000 & $0,004^{5}$ & 0,000 & 0,000 \\
\hline White/Koenker & 0,020 & 0,020 & 0,210 & 0,671 & 0,007 & 0,007 & 0,009 & 0,009 & 0,201 & 0,531 & 0,000 & 0,000 \\
\hline Subidentificação ${ }^{2}$ & 0,071 & 0,009 & 0,000 & 0,000 & 0,005 & 0,005 & 0,028 & 0,028 & 0,000 & 0,000 & 0,046 & 0,046 \\
\hline Identificação Fraca ${ }^{3}$ & 7,784 & 7,230 & 8,080 & 7,658 & 6,633 & 6,633 & 13,770 & 13,770 & 8,575 & 7,230 & 13,972 & 13,972 \\
\hline Instrumento Fraco ${ }^{4}$ & 0,000 & 0,000 & 0,000 & 0,000 & 0,000 & 0,000 & 0,000 & 0,000 & 0,000 & 0,000 & 0,000 & 0,000 \\
\hline Estat. J de Hansen & 0,138 & 0,279 & 0,933 & 0,308 & 0,184 & 0,497 & 0,191 & 0,333 & 0,920 & 0,094 & 0,177 & 0,594 \\
\hline
\end{tabular}

Notas: ${ }^{1}$ Valores indicados dos testes de especificação são p-valores, exceto para o teste de identificação fraca, que é representado pela estatística F; ${ }^{2}$ Kleibergen-Paap rk LM statistic; ${ }^{3}$ Kleibergen-Paap Wald rk F statistic; ${ }^{4}$ Teste de Anderson-Rubin; ${ }^{5}$ Resultado do teste para AR(2). 
Tabela C.2: Estimações Utilizando o Filtro $\mathrm{CF}^{1}$

\begin{tabular}{|c|c|c|c|c|c|c|c|c|}
\hline & (I) & (II) & (III) & $(\mathrm{IV})$ & (V) & $(\mathrm{VI})$ & (VII) & (VIII) \\
\hline & GMM2S & $\begin{array}{c}\text { GMM- } \\
\text { CUE }\end{array}$ & GMM2S & $\begin{array}{c}\text { GMM- } \\
\text { CUE }\end{array}$ & GMM2S & $\begin{array}{l}\text { GMM- } \\
\text { CUE }\end{array}$ & GMM2S & $\begin{array}{c}\text { GMM- } \\
\text { CUE }\end{array}$ \\
\hline & $\widetilde{y}=\widetilde{y}_{P I B}$ & $\widetilde{y}=\widetilde{y_{P I B}}$ & $\widetilde{y}=\widetilde{y}_{I N D}$ & $\widetilde{y}=\widetilde{y}_{I N D}$ & $\widetilde{y}=\widetilde{y}_{I B C}$ & $\widetilde{y}=\widetilde{y}_{I B C}$ & $\widetilde{y}=\widetilde{y_{E}} \boldsymbol{P P}$ & $\widetilde{y}=\widetilde{y} E M P$ \\
\hline Cumby-Huizinga AR(1) & 0,000 & 0,000 & 0,000 & 0,000 & 0,000 & 0,000 & 0,000 & 0,000 \\
\hline White/Koenker $n R_{C}^{2}$ & 0,008 & 0,008 & 0,000 & 0,000 & 0,000 & 0,000 & 0,000 & 0,000 \\
\hline Subidentificação $^{2}$ & 0,339 & 0,047 & 0,189 & 0,080 & 0,196 & 0,053 & 0,095 & 0,095 \\
\hline Identificação Fraca ${ }^{3}$ & 30,055 & 14,975 & 13,781 & 12,414 & 11,272 & 10,113 & 12,338 & 12,338 \\
\hline Instrumento Fraco ${ }^{4}$ & 0,000 & 0,000 & 0,000 & 0,000 & 0,000 & 0,000 & 0,000 & 0,000 \\
\hline Estat. J de Hansen & 0,268 & 0,405 & 0,136 & 0,421 & 0,112 & 0,376 & 0,131 & 0,415 \\
\hline
\end{tabular}

Notas: ${ }^{1}$ Valores indicados dos testes de especificação são p-valores, exceto para o teste de identificação fraca, que é representado pela estatística F; ${ }^{2}$ Kleibergen-Paap rk LM statistic; ${ }^{3}$ Kleibergen-Paap Wald rk F statistic; ${ }^{4}$ Teste de Anderson-Rubin; ${ }^{5}$ Resultado do teste para $\operatorname{AR}(2)$. 